NBER WORKING PAPER SERIES

\title{
THE DISTRIBUTION OF STOCK RETURN VOLATILITY
}

\author{
Torben G. Andersen \\ Tim Bollerslev \\ Francis X. Diebold \\ Heiko Ebens \\ Working Paper 7933 \\ http://www.nber.org/papers/w7933 \\ NATIONAL BUREAU OF ECONOMIC RESEARCH \\ 1050 Massachusetts Avenue \\ Cambridge, MA 02138 \\ October 2000
}

This work was supported by the National Science Foundation. We thank the Editor and Referee for several suggestions that distinctly improved this paper. Helpful comments were also provided by Dave Backus, Michael Brandt, Rohit Deo, Rob Engle, Clive Granger, Lars Hansen, Joel Hasbrouck, Ludger Hentschel, Cliff Hurvich, Pedro de Lima, Bill Schwert, Rob Stambaugh, George Tauchen, and Stephen Taylor, as well as seminar and conference participants at the 1999 North American Winter Meetings and European Summer Meetings of the Econometric Society, the May 1999 NBER Asset Pricing Meeting, Boston University, Columbia University, Johns Hopkins University, London School of Economics, New York University, Olsen \& Associates, the Triangle Econometrics Workshop, and the University of Chicago. Much of this paper was written while Diebold visited the Stern School of Business, New York University, whose hospitality is gratefully acknowledged. The views expressed are those of the authors and not necessarily those of the National Bureau of Economic Research.

(C) 2000 by Torben G. Andersen, Tim Bollerslev, Francies X. Diebold, and Heiko Ebens. All rights reserved. Short sections of text, not to exceed two paragraphs, may be quoted without explicit permission provided that full credit, including $\mathbb{C}$ notice, is given to the source. 
The Distribution of Stock Return Volatility

Torben G. Andersen, Tim Bollerslev, Francis X. Diebold and Heiko Ebens

NBER Working Paper No. 7933

October 2000

\begin{abstract}
We exploit direct model-free measures of daily equity return volatility and correlation obtained from high-frequency intraday transaction prices on individual stocks in the Dow Jones Industrial Average over a five-year period to confirm, solidify and extend existing characterizations of stock return volatility and correlation. We find that the unconditional distributions of the variances and covariances for all thirty stocks are leptokurtic and highly skewed to the right, while the logarithmic standard deviations and correlations all appear approximately Gaussian. Moreover, the distributions of the returns scaled by the realized standard deviations are also Gaussian. Consistent with our documentation of remarkably precise scaling laws under temporal aggregation, the realized logarithmic standard deviations and correlations all show strong temporal dependence and appear to be well described by long-memory processes. Positive returns have less impact on future variances and correlations than negative returns of the same absolute magnitude, although the economic importance of this asymmetry is minor. Finally, there is strong evidence that equity volatilities and correlations move together, possibly reducing the benefits to portfolio diversification when the market is most volatile. Our findings are broadly consistent with a latent volatility fact or structure, and they set the stage for improved high-dimensional volatility modeling and out-ofsample forecasting, which in turn hold promise for the development of better decision making in practical situations of risk management, portfolio allocation, and asset pricing.
\end{abstract}

Torben G. Andersen

Department of Finance

Kellogg Graduate School of Management

Northwestern University

Evanston, IL 60208

and NBER

phone: 847-467-1285

t-andersen@nwu.edu

Francis X. Diebold

Department of Economics

University of Pennsylvania

Philadelphia, PA 19104-6297

and NBER

phone: 215-898-1507

fdiebold@mail.sas.upenn.edu
Tim Bollerslev

Department of Economics

Duke University

Durham, NC 27708

and NBER

phone: 919-660-1846

boller@econ.duke.edu

Heiko Ebens

Department of Economics

Johns Hopkins U niversity

Baltimore, MD 21218

phone: 41 0-516-7601

ebens@jhu.edu 


\section{Introduction}

Financial market volatility is central to the theory and practice of asset pricing, asset allocation, and risk management. Although most textbook models as sume volatilities and corre lations to be constant, it is widely recognized among both finance academics and practitioners that they vary importantly over time. This recognition has spurred an extensive and vibrant research program into the distributional and dynam ic properties of stock market volatility. ${ }^{1}$ Most of what we have learned from this burgeoning literature is based on the estimation of parametric AR CH or stochastic volatility models for the underlying returns, or on the analysis of implied volatilities from options or other derivatives prices. However, the validity of such volatility measures generally depends upon specific distributional assumptions, and in the case of implied volatilities, further assumptions concerning the market price of volatility risk. As such, the existence of multiple competing models immediately calls into question the robustness of previous findings. An alternative approach, based for example on squared returns over the relevant return horizon, provides model-free unbiased estimates of the ex-post realized volatility. Unfortunately, however, squared returns are also a very noisy volatility indicator and hence do not allow for reliable inference regarding the true underlying latent volatility.

The limitations of the traditional procedures motivate the different approach for measuring and analyzing the properties of stock market volatility adopted in this paper. Using continuously recorded transactions prices, we construct estimates of ex-post realized daily volatilities by summing squares and cross -products of intraday high-fre quency returns. Volatility estimates so constructed are modelfree, and as the sampling frequency of the returns approaches infinity, they are also, in theory, free from measurement error (Andersen, Bollerslev, Diebold and Labys, henceforth ABDL, 2000). ${ }^{2}$ The need for reliable high-frequency return observations suggests, however, that our approach will work most effectively for actively traded stocks. We focus on the thirty stocks in the Dow Jones Industrial

\footnotetext{
1 For an early survey, see Bollerslev, Chou and Kroner (1992). A selective and incomplete list of studies since then includes Andersen (1996), Bekaert and Wu (2000), Bollerslev and Mikkelsen (1999), Braun, Nelson and S unier (1995), Breidt, Crato and de Lima (1998), Campbell and Hentschel (1992), Campbell et al. (2000), Canina and Figlewski (1993), Cheung and Ng (1992), Christensen and Prabhala (1998), Day and Lewis (1992), Ding, Granger and Engle (1993), Du ffee (1995), Engle and Ng (1993), Engle and Lee (1993), Gallant, Rossi and Tauchen (1992), Glosten, Jagannathan and Runkle (1993), Hentschel (1995), Jacquier, Polson and Rossi (1994), Kim and Kon (1994), Kroner and Ng (1998), Kuwahara and Marsh (1992), Lamoureux and Lastrapes (1993), and Tauchen, Zhang and Liu (1996).

2 Nelson (1990, 1992) and Nelson and Foster (1994) obtain a related by different result: mis-specified ARCH models may work as consistent filters for the latent instantaneous volatility as the return horizon approaches zero. Similarly, Ledoit and Santa-Clara (1998) show that the Black-Scholes implied volatility for an at-the-money option provides a consistent estim ate of the und erlying laten $t$ instan taneous volatility as the time to $m$ aturity ap proaches zero.
} 
Average (DJIA), both for computational tractability and because of our intrinsic interest in the Dow, but the empirical findings carry over to a random sample of thirty other liquid stocks. In spite of restricting the analysis to actively traded stocks, market microstructure frictions, including price discreteness, infrequent trading, and bid-ask bounce effects, are still operative. In order to mitigate these effects, we use a five-minute return horizon as the effective "continuous time record." Treating the resulting daily time series of realized variances and covariances constructed from a five-year sample of five-minute returns for the thirty DJIA stocks as being directly observable allows us to characterize the distributional features of the volatilities without attempting to fit multivariate ARCH or stochastic volatility models.

Our approach is directly in line with earlier work by French, Schwert and Stambaugh (1987), Schwert (1989, 1990a, 1990b), and Schwert and Seguin (1991), who rely primarily on daily return observations for the construction of monthly realized stock volatilities. ${ }^{3}$ The earlier studies, however, do not provide a formal justification for such meas ures, and the diffusion-theoretic underpinnings provided here explicitly hinge on the length of the return horizon app roaching zero. Intuitively, following the work of Merton (1980) and Nelson (1992), for a continuous time diffusion process, the diffusion coefficient can be estimated arbitrarily well with sufficiently finely sampled observations, and by the theory of quadratic variation, this same idea carries over to estimates of the integrated volatility over fixed horizons. As such, the use of high-frequency returns plays a critical role in justifying our measur ements. Moreover, our focus centers on daily, as oppos ed to monthly, volatility measures. This mirrors the focus of most of the extant academ ic and indus try volatility literatures and more cle arly highlights the important intertemporal volatility fluctuations. ${ }^{4}$ Finally, because our methods are trivial to implement, even in the high-dimensional situations relevant in practice, we are able to study the distributional and dynamic properties of correlations in much greater depth than is possible with traditional multivariate $\mathrm{ARCH}$ or stochastic volatility models, which rapidly become intractable as the number of assets grows.

\footnotetext{
3 In a related analysis of monthly U.S. stock market volatility, Cam pbell et al. (2000) augm ent the time series of monthly sample standard deviations with various alternative volatility mea sures based on the dispersion of the retu rns on individual stocks in the market index.

4 Schwert (1990a), Hsieh (1991), and Fung and Hsieh (1991) also study daily standard deviations based on 15-min ute equity retums. However, their analysis is strictly univariate and decidedly less broad in scope than ours.
} 
Turning to the results, we find it useful to segment them into unconditional and conditional aspects of the distributions of volatilities and correlations. As regards the unconditional distributions, we find that the distributions of the realized daily variances are highly non-normal and skewed to the right, but that the logarithms of the realized variances are approximately normal. Similarly, although the unconditional distributions of the covariances are all skewed to the right, the realized daily correlations appear approximately normal. Finally, although the unconditional daily return distributions are leptokurtic, the daily returns normalized by the realized standard deviations are also close to normal. Rather remarkably, these results hold for the vast majority of the 30 volatilities and 435 covariances/correlations associated with the 30 Dow Jones stocks, as well as the 30 actively traded stocks in our randomly selected control sample.

Moving to conditional aspects of the distributions, all of the volatility measures fluctuate substantially over time, and all display strong dynamic dependence. Moreover, this dep endence is well-characterized by slowly mean reverting fractionally integrated process es with a degree of integration, $d$, around 0.35 , as further underscored by the existence of very precise scaling laws under temporal aggregation. Although statistically significant, we find that the much debated leverage-effect, or as ymmetry in the relationship betw een past ne gative and positive returns and future volatilities, is relatively unimportant from an economic perspective. Interestingly, the same type of asymmetry is also present in the realized correlations. Finally, there is a systematic tendency for the variances to move together, and for the correlations among the different stocks to be high/low when the variances for the underlying stocks are high/low, and when the correlations among the other stocks are also high/low.

Although several of these features have been documented previously for U.S. equity returns, the existing evidence relies almost exclusively on the estimation of specific parametric volatility models. In contrast, the stylized facts for the thirty DJIA stocks doc umented here are ex plicitly modelfree. Moreover, the facts extend the existing results in important directions and both solidify and expand on the more limited set of results for the two exchange rates in ABDL (1999a, 2000) and the DJIA stock index in Ebens (1999a). As such, our findings set the stage for the development of improved volatility models - possibly involving a simple factor structure, which appears cons istent with many of our empirical findings - and corres ponding out-of-sample volatility forecasts, consistent 
with the distributional characteristics of the returns. ${ }^{5}$ Of course, the practical use of such models in turn should allow for better risk management, portfolio allocation, and asset pricing decisions.

The remainder of the paper is organized as follows. In section 2 we provide a brief account of the diffusion-theoretic underpinnings of our realized volatility measures, along with a discus sion of the actual data and volatility calculations. In section 3 we discus s the unconditional univariate return, volatility and correlation distributions, and we move to dynamic aspects, including long-memory effects and scaling laws, in section 4 . In section 5 we assess the symmetry of responses of realized volatilities and correlations to unexpected shocks. We report on multivariate aspects of the volatility and correlation distributions in section 6 , and in section 7 we illustrate the consistency of several of our empirical results with a simple model of factor structure in volatility. We conclude in section 8 with a brief summary of our main findings and some sugge stions for future research.

\section{Realized Volatility Measurem ent}

\subsection{Theory}

Here we provide a discussion of the theoretical justification behind our volatility measurements. For a more thorough treatment of the pertinent issues within the context of special semimartingales we refer to ABDL (2000) and the general discus sion of stochastic integration in Protter (1992). To set out the basic idea and intuition, assume that the $\log$ arithmic $N \times 1$ vector price process, $p_{t}$, follows a multivariate continuous-time stochastic volatility diffusion,

$$
d p_{t}=\mu_{t} d t+\Omega_{t} d W_{t},
$$

where $W_{t}$ denotes a standard $N$-dimensional Brownian motion, the process for the $N \times N$ positive definite diffusion matrix, $\Omega_{t}$, is strictly stationary, and we normalize the unit time interval, or $h=1$, to repres ent one trading day. Conditional on the sample path realization of $\mu_{t}$ and $\Omega_{t}$, the distribution of the continuously compounded $h$-period returns, $r_{t+h, h} \equiv p_{t+h}-p_{t}$, is then

$$
r_{t+h, h} \mid \sigma\left\{\mu_{t+\tau}, \Omega_{t+\tau}\right\}_{\tau=0}^{h} \sim N\left(\int_{0}^{h} \mu_{t+\tau} d \tau, \int_{0}^{h} \Omega_{t+\tau} d \tau\right),
$$

\footnotetext{
${ }^{5}$ Ebens (1999a), for example, makes an initial attempt at modeling univariate realized stock volatility for the DJIA index.
} 
where $\sigma\left\{\mu_{t+\tau}, \Omega_{t+\tau}\right\}_{\tau=0}^{h}$ denotes the $\sigma$-field generated by the sample paths of $\mu_{t+\tau}$ and $\Omega_{t+\tau}$ for $0 \leq \tau \leq h$. The integrated diffusion matrix thus provides a natural measure of the true latent $h$-period volatility. This notion of integrated volatility already plays a central role in the stochastic volatility option pricing literature, where the price of an option typically depends on the distribution of the integrated volatility process for the underlying asset over the life of the option. ${ }^{6}$

By the theory of quadratic variation, we have that under weak regularity conditions,

$$
\Sigma_{j=1, \ldots,[h / \Delta]} r_{t+j \Delta, \Delta} \cdot r_{t+j \cdot \Delta, \Delta}^{\prime}-\int_{0}^{h} \Omega_{t+\tau} d \tau \rightarrow 0
$$

almost surely for all $t$ as the sampling frequency of the returns increases, or $\Delta \rightarrow 0$. Thus, by summing sufficiently finely-sampled high-frequency returns, it is possible to construct ex-post realized volatility measures for the integrated latent volatilities that are asymptotically free of measurement error. ${ }^{7}$ This contrasts sharply with the common use of the cross-product of the $h$-period returns, $r_{t+h, h} \cdot r_{t+h, h}^{\prime}$, as a simple ex-post volatility measure. Although the squared return over the forecast horizon provides an unbiased es timate for the realized integrated volatility, it is an extremely noisy estimator, and predictable variation in the true latent volatility process is typically dwarfed by measurement error. ${ }^{8}$ Moreover, for longer horizons any conditional mean dependence will tend to contaminate this variance measure. In contrast, as the length of the return horizon decreases the impact of the drift term vanishes, so that the mean is effectively annihilated.

These ass ertions remain valid if the underlying continuous time process in equation (1) contains jumps, so long as the price process is a special semimartingale, which will hold if it is arbitrage-free (see, e.g., B ack, 1991). Of course, in this case the limit of the summation of the high-frequency returns will involve an additional jump component, but the interpretation of the sum as the realized $h$-period

6 See, for example, the well-known contribution of Hull and White (1987).

${ }^{7}$ Consider the simple case of univariate discretely sampled i.i.d. normally distributed mean-zero returns; i.e., $N=1, \mu_{t}$ $=0$, and $\Omega_{t}=\sigma^{2}$. It follows by standard arguments that $E\left(h^{-1} \cdot \Sigma_{j=1, \ldots,[h / \Delta]} r_{t+j \cdot \Delta, \Delta}^{2}\right)=\sigma^{2}$, while $\operatorname{Var}\left(h^{-1} \cdot \Sigma_{j=1, \ldots,[h / \Delta]} r_{t+j \cdot \Delta, \Delta}^{2}\right)=$ $(\Delta / h) \cdot 2 \cdot \sigma^{4} \rightarrow 0$, as $\Delta \rightarrow 0$.

8 In empiric ally rea listic situ ation s, the varia nce of $r_{t+1,1} r_{t+1,1}^{\prime}$ is easily twenty times the variance of the true daily integrated volatility, $\int_{0}^{1} \Omega_{t+\tau} d \tau$; see Andersen and Bollerslev (1998) for some numerical results along these lines. 
return vola tility remains intact; for further disc uss ion along thes e lines see ABDL (2000). Importantly, in the presence of jumps the conditional distribution of the returns in equation (2) is no longer Gaussian. As such, the corresponding em pirical distribution of the standardized returns speaks directly to the relevance of allowing for jumps in the underlying continuous time process when analyzing the returns over longer $h$-period horizons. Of course, viewed as a non-parametric omnibus test for jumps, this may not be a very powerful procedure. ${ }^{9}$

\subsection{Data}

Our empirical analysis is based on data from the TAQ (Trade And Quotation) database. The TAQ data files contain continuously recorded information on the trades and quotations for the securities listed on the New Y ork Stock Exchange (NYSE), American Stock Exchange (AMEX), and the National As sociation of Security Dealers A utomated Quotation system (NASDAQ). The database is published monthly, and has been available on CD-ROM from the NYSE since January 1993; we refer the reader to the corresponding data manual for a more complete description of the actual data and the method of data-capture. Our sample extends from January 2, 1993 until May 29, 1998, for a total of 1,366 trading days. A complete analysis based on all trades for all stocks, although straightforward conceptually, is infeasible in practice. We therefore restrict our analysis to the thirty DJIA firms, which also helps to ensure a reasonable degree of liquidity. A list of the relevant ticker symbols as of the reconfiguration of the DJIA index in March 1997 is contained in Andersen, Bollerslev, Diebold and Ebens (2000) (henceforth, ABDE).

Although the DJIA stocks are among the most actively traded U.S. equities, the median intertrade duration for all stocks across the full sample is 23.1 seconds, ranging from a low of 7 seconds for Merck \& Co. Inc. (MRK) to a high of 54 seconds for United Technologies Corp. (UTX). As such, it is not practically feasible to push the continuous record asymptotics and the length of the observation interval $\Delta$ in equation (3) beyond this level. Moreover, because of the organizational structure of the market, the available quotes and transaction prices are subject to discrete clustering and bid-ask bounce effects. Such market microstructure features are generally not important when analyzing longer horizon interdaily returns but can seriously distort the distributional properties of high-frequency intraday returns; see, e.g., the textbook treatment by Campbell, Lo and MacKinlay (1997). Thus,

\footnotetext{
9 A similar idea underlies the test for jumps in Drost, Nijman and Werker (1998), based on a comparison of the sample kurtosis and the population kurtosis implied by a continuous time GA RCH(1,1) model; see also A BDL (1999a).
} 
following the analysis in Andersen and Bollerslev (1997), we rely on artificially constructed fiveminute returns. ${ }^{10}$ With the daily transaction record extending from 9:30 EST until 16:05 EST, there are a total 79 five-minute returns for each day, corresponding to $\Delta=1 / 79 \approx 0.0127$ in the notation above. The five-minute horizon is short enough so that the accuracy of the continuous record asymptotics underlying our realized volatility measures w ork well, and long enough so that the confounding influences from market microstructure frictions are not overwhelming; see ABDL (1999b) for further discussion along these lines. ${ }^{11}$

\subsection{Construction of Realized Equity Volatilities}

The five-minute return series are constructed from the logarithmic difference between the prices recorded at or immediately be fore the corresponding five-minute marks. Although the limiting res ult in equation (3) is independent of the value of the drift parameter, $\mu_{t}$, the use of a fixed discrete time interval may allow depend ence in the mean to syste matic ally bias our volatility measures. Thus, in order to purge the high-frequency returns of the negative serial correlation induced by the uneven spacing of the observed prices and the inherent bid-ask spread, we first es timate an MA(1) model for each of the five-minute return series using the full five-year sample. Consistent with the spurious dependence that would be induced by non-synchron ous trading and bid-ask bounce effects, all estimated moving-average coefficients are negative, with a median value of -0.214 across the thirty stocks. We denote the corre sponding thirty demeaned MA(1)-filtered return series of $79 \times 1,366=$ 107,914 five-minute returns by $r_{t+\Delta, \Delta} \cdot{ }^{12}$ Finally, to avoid any confusion, we denote the daily unfiltered raw returns by a single time subscript; i.e., $r_{t}$ where $t=1,2, \ldots, 1,336$.

The realized daily covariance matrix is then

$$
\operatorname{Cov}_{t} \equiv \Sigma_{j=1, \ldots, 1 \Delta} r_{t+j \Delta, \Delta} \cdot r_{t+j \cdot \Delta, \Delta}^{\prime}
$$

\footnotetext{
10 An alternative, and much more complicated approach, would be to utilize all of the observations by explicitly modeling the high-frequency frictions.

11 As detailed below, the average daily variance of the "typical" DJIA stock equals 3.109. Thus, in the case of i.i.d. normally distributed returns, it follows that a five-minute sampling frequency translates into a variance for the daily varia nce es tima tes of 0.245 .

12 We also experimented with the use of unfiltered and linearly interpolated five-minute returns, which produced very similar results.
} 
where $t=1,2, \ldots, 1,366$ and $\Delta=1 / 79$. For notational simplicity we refer to realized daily variances given by the diagonal elements as $v_{j, t}^{2} \equiv\left\{\operatorname{Cov}_{t}\right\}_{j, j}$, and the corresponding daily logarithmic standard deviations as $l v_{j, t} \equiv \log \left(v_{j, t}\right)$. Similarly, we denote the realized daily correlations by $\operatorname{Corr}_{i, j, t} \equiv\left\{\operatorname{Cov}_{t}\right\}_{i, j} /($ $\left.v_{i, t} \cdot v_{j, t}\right)$. In addition to the daily measures, we also briefly consider the statistical properties of various multi-day volatility measures, whose construction follows in straightforward fashion from equation (4) by extending the summation to cover $h / \Delta$ intervals, where $h>1$ denotes the multiday horizon.

Because volatility is now effectively observable, we may rely on conventional statistical procedures for characterizing its distributional properties. In the next section we proceed to do so. Of course, it is possible the thirty DJIA stocks analyzed here do not provide a representative picture of the return volatility for other actively traded stocks. As a robustness check we replicated the empirical analysis for a set of thirty randomly selected liquid stocks, picked from the 214 stocks with at least 158 trades per day at the beginning, middle and end of the sample period. Importantly, all of the results for this randomly selected sample match closely those reported below for the DJIA stocks, thus underscoring the general nature of our findings. However, for rea sons of space conservation, we shall not discuss the parallel empirical findings here; instead, we refer the interested reader to ABDE (2000) for detailed discussion and a full set of tables.

\section{Univariate Unconditional Return and Volatility Distributions}

\subsection{Returns}

A voluminous literature, seeking to characterize the unconditional distribution of speculative retums, has evolved over the past three decades. ${ }^{13}$ Cons istent with this litera ture, the summary statistics in Table 1 show that the daily DJIA returns, $r_{j, t}$, have fatter tails than the normal and, for the majority of the stocks, are also skewed to the right. ${ }^{14}$

Quite remarkably, however, the next set of numbers in Table 1 indicate that all of the thirty standardized return series, $r_{j, t} / v_{j, t}$, are approximately unconditionally normally distributed. In particular,

13 In early contributions, M andelbrot (1963) and F ama (1965) argued that the Stab le Paretian dis tributions provide a good approximation. Subsequently, however, Praetz (1972) and Blattberg and Gonedes (1974), among many others, found that finite variance-mixtures of normals, such as the student-t distribution, generally afford better characterizations.

14 Under the null hypothesis of i.i.d. normally distributed returns, the sample skewn ess and kurtosis are as ymptotically normal with means of 0 and 3 , and variances of $6 / T$ and $24 / T$, where $T$ denotes sample size. Thus for $T=1,366$ the two standard errors are 0.066 and 0.133 . 
the median value of the sample kurtosis is reduced from 5.416 for the raw returns to only 3.129 for the standardized returns. This is also evident from Figure 1, which plots the kernel density estimate for the mean-zero and unit-variance standardized returns for Alcoa Inc. (AA), the first of the thirty DJIA stocks, alphabetically by ticker symbol. The close approximation afforded by the normal reference density is striking. ${ }^{15}$ This result stands in sharp contrast to the leptokurtic distributions for the standardized daily returns that typically obtain when relying on an estimate of the one-day-ahead conditional variance from a param etric ARCH or stochastic volatility model; s ee e.g., Bollers lev, Engle and Nelson (1994) for a general discussion, and Kim and Kon (1994) for explicit results related to the distributions of the DJIA stocks over an earlier time period. The results in Table 1 also imply that the unconditional distribution for the returns should be well approximated by a continuous variance mixture of normals, as determined by the unconditional distribution for the mixing variable, $v_{j, t}^{2}$. The following section details this distribution.

\subsection{Variances and Logarithmic Standard Deviations}

The first four columns in Table 2 provide the same set of summary statistics for the unconditional distribution of the realized daily variances. The median value for the sample means is 3.109, implying an annualized standard deviation for the typical stock of around 28 perc ent. However, there is considerable variation in the average volatility across the thirty stocks, ranging from a high of 42 percent for Walmart Stores Inc. (WMT) to a low of 22 percent for UTX. ${ }^{16}$ The standard deviations given in the second column also indic ate that the realized daily volatilities fluc tuate significantly through time. Finally, it is evident from the third and the fourth columns that the distributions of the realized variances are extrem ely right-skewed and leptokurtic. This may seem surprising, as the realized daily variances are based on the sum of 79 five-minute return observations. However, as emphasized by Andersen, Bollerslev and Das (2000), intraday specu lative returns are strongly dependent so that, even with much larger samples, standard Central Limit Theorem arguments often provide very poor approximations in the high-frequency data context.

The next part of Table 2 refers to the realized logarithmic standard deviations, $l v_{j, t}$.

\footnotetext{
15 The kernel density estim ates are based on a Gaus sian kernel and Silverman's (1986) bandwid th. Similar plots for all of the other stocks are available in ABDE (2000).

16 Details regarding the individual s tocks are again available in ABDE (2000).
} 
Intere stingly, the median value of the sample skewness acros s all of the thirty stocks is re duc ed to only 0.192, compared to 5.609 for the realized variances and, although the sample kurtos is for all but one of the stocks exceed the normal value of three, the assumption of norm ality is obviously much better in this case. This is also illustrated by Figure 2, in which we show estimates of the standardized unconditional density for $l v_{A A, t}$, along w ith the standard normal density. The normal approximation is very good.

This evidence is consistent with Taylor (1986) and French, Schwert and Stambaugh (1987), who find that the dis tribution of logarithmic monthly stand ard deviations cons tructed from the daily returns within the month is close to Gaussian. It is also directly in line with the recent evidence in ABDL (2000) and Zumbach et al. (1999), which indicates that realized daily foreign exchange rate volatilities constructed from high-frequency data are approximately log-normally distributed. Taken together, the results in Tables 1 and 2 imply that the unconditional distribution for the daily returns should be well described by a continuous lognormal-normal mixture, as advocated by Clark (1973) in his seminal treatment of the Mixture-of-Distributions-Hypothesis (MDH). The results for the foreign exchange rates in ABDL (1999c) corroborate this idea.

Our discussion thus far has centered on univariate return and volatility distributions. However, asset pricing, portfolio selection, and risk management decisions are invariably multivariate, involving many assets, with correlated returns. The next section summarizes the unconditional distributions of the pertinent realized covariances and correlations.

\subsection{Covariances and Correlations}

The realize d covariance matrix for the thirty DJIA stocks contains a total of 435 unique elem ents. In Table 3 we report the median value of the sample mean, standard deviation, skewness, and kurtosis for the covariances and correlations for each of the thirty stocks with respect to all of the twenty-nine other stocks; i.e., the median value of the particular sample statistic across the 29 time series for stock $i$ as defined by $\operatorname{Cov}_{i, j, t}$ and $\operatorname{Corr}_{i, j, t}$, where $j=1,2, \ldots, 30$, and $j \neq i$.

The median of the mean covariance across all of the stocks equals 0.373 , while the typical correlation among the DJIA stocks is around 0.113. However, the realized covariances and correlations exhibit considerable variation across the different stocks and across time. For instance, the median of the average correlations for Union Carbide Corp. (UK) equals 0.080, whereas the median for General Electric (GE) is as high as 0.150. 
As with the realized variances, the distributions of the realized covariances are extremely right skew ed and leptokurtic. Interestingly, how ever, the realize d correlations ap pear approximately normally distributed. In particular, the median kurtosis for all of the 435 realized covariances equals 61.86, whereas the median kurtosis for the realized correlations equals 3.037. To illustrate this result, Figure 3 graphs the unconditional distribution of the standardized realized correlations for AA with respect to Exxon Corp. (XON), the alphabetically last ticker symbol of the thirty DJIA stocks. ${ }^{17}$ It is obvious that the standard normal reference density affords a close approx imation.

The unconditional distributions detailed above capture important aspects of the return generating process, and they indicate that all of the realized volatilities vary importantly through time. In the next section, we explore the associated dynamic dependence. Again, the use of realized volatilities allows us to do so in a model-free environment, without reliance on complicated and intractable parametric latent volatility models.

\section{Temporal Dependence, Long-Mem ory and Scaling}

The conditional distribution of stock market volatility has been the subject of extensive research effort during the past decade. Here we solidify and extend the findings in that literature; in particular, we reinforce the existence of pronounced long-run dependence in volatility and show that this effect is also pres ent in correlations. Motivated by the results of the previous section, we focus on the logarithmic volatilities and correlations.

\subsection{Logarithmic Standard Deviations}

It is instructive first to consider the representative time series plot for $l v_{A A, t}$ in Figure 4. It is evident that the series is positively serially corre lated, with distinct periods of high and low vola tility readily identifiable. This is, of course, a manifestation of the well docum ented volatility clustering effect, and directly in line with the results reported in the extant $\mathrm{ARCH}$ and stochastic volatility literatures; see, e.g., Lamoureux and Lastrapes (1990) or Kim and Kon (1994) for es timation of GARCH models for individual daily stock returns.

To underscore the significance of this effect more generally, the first column in Table 4 summarizes the values of the standard Ljung-Box portmanteau test for the joint significance of the first

\footnotetext{
17 Similar graphs for all of the other correlations with respect to XON are available in ABDE (2000).
} 
22 autocorrelations of $l v_{j, t}$ (about one month of trading days). The hypothesis of zero au tocorrelations is overwhelmingly rejected for all thirty stocks. The correlogram for AA in Figure 5 shows why. The autocorrelations are systematically above the conventional Bartlett ninety-five percent confidence band, the upper range of which is given by the flat dashed line, even at the longest displacement of 120 days (approximately half a year). Similarly slow decay rates have been documented in the literature with daily time series of absolute or squared returns spanning several decades (e.g., Crato and de Lima, 1993, and Ding, Granger and Engle, 1993), but the results in Figure 5 are notew orthy in that the sample "only" spans five-and-a-half years. In spite of this slow decay, the augmented Dickey-Fuller tests, reported in the second column in Table 4, reject the null hypothesis of a unit root for all but four of the stocks when judged by the conventional -2.86 five-percent critical value. ${ }^{18}$

In response to such findings, a number of recent studies have argued that the long-run dependence in financial market volatility may be conveniently modeled by fractional integrated $\mathrm{ARCH}$ or stochastic volatility models; see, e.g., Baillie, Bollerslev and Mikkelsen (1996), Breidt, Crato and de Lima (1998) and Robinson and Zaffaroni (1998). The log-periodogram regression estimates for the degree of fractional integration, or $d$, for the realized logarithmic volatilities, given in the third column in Table 4, are directly in line with these studies, and all thirty estimates are very close to the median value of 0.349 (see Gew eke and Porter-Hudak, 1993, and Robinson, 1995, for formal discussion of the log-periodogram regression, often called GPH, technique), and highly statistically significantly different from both 0 and $1 .{ }^{19}$ It is also evident that the implied hyperbolic decay rate, $j^{2 \cdot d-1}$, superim posed in Figure 5, affords a close approximation to the correlogram for $l v_{A A, t}$, and equally good fits obtain for each of the 29 other stocks.

18 It is well known, however, that the outcome of standard unit root tests should be carefully interpreted with slowly decaying processes; see, e.g., Schwert (1987).

19 The slow hyperbolic decay of the long-lag autocor relations, or equival ently the log-lin ear ex plosion of the low-fre quency spectrum, are both distinguishing features of a covariance stationary fractionally integrated, or I(d), process with $0<d<1 / 2$. Accordingly, let $I\left(\omega_{j}\right)$ denote the sample periodogram estimate for the spectrum at the $j$ th Fourier frequency, $\omega_{j}=2 \pi j / T, j=1$, $2, \ldots,[T / 2]$. The GPH estimator for $d$ is then based on the least squares regression,

$$
\log \left[I\left(\omega_{j}\right)\right]=\beta_{0}+\beta_{i} \cdot \log \left(\omega_{j}\right)+u_{j},
$$

where $j=1,2, \ldots, m$, and $\hat{d} \equiv-1 / 2 \cdot \beta_{1}$ is asymptotically normal with a standard error of $\pi \cdot(24 \cdot m)^{-1 / 2}$. For the estimates in Table 4 we took $m=[1,366]^{3 / 5}=76$, thus implying an asymptotic standard er ror of 0.074 . This particular choice was motivated by Deo and Hurvich (1999), who show that the GPH estimator is consistent and asymptotically normal provided that $m=O\left(T^{-\delta}\right)$, where $\delta<4 d \cdot(1+4 d)^{-1}$. 
Another implication of the long-memory associated with fractional integration concerns the behavior of the variance of partial sums. In particular, let $\left[x_{t}\right]_{h} \equiv \Sigma_{j=1, \ldots, h} x_{h \cdot(t-1)+j}$, denote the $h$-fold partial sum process for $x_{t}$. If $x_{t}$ is fractionally integrated, the partial sums will obey a scaling law of the form $\operatorname{Var}\left(\left[x_{t}\right]_{h}\right)=c \cdot h^{2 d+1}$. Thus, given $d$ and the unconditional variance at one aggregation level, it is possible to calculate the implied variance for any other aggregation level. To explore whether this implication of fractional integration is satisfied by our equity volatilities, we plot in Figure 6 the logarithm of the variance of the partial sum of the daily realized logarithmic standard deviations, $\log \left(\operatorname{Var}\left[l_{A A, t}\right]_{h}\right)$, against the logarithm of the aggregation level, $\log (h)$, for $h=1,2, \ldots, 30$. The accuracy of the fitted line, $c+(2 d+1) \cdot \log (h)$, is striking. ${ }^{20}$ Moreover, the corresponding regression estimates for $d$ for all of stocks reported in the fourth column in Table 4, are generally very close to the GPH estimates.

\subsection{Correlations}

The estimation of parametric multivariate volatility models is notoriously difficult and, as a result, relatively little is known about the temporal behavior of individual stock return correlations. ${ }^{21}$ The last four columns of Table 4 provide our standard menu of summary statistics for the 435 series of daily realized correlations. In accord ance with our convention in section 3.3 above, each entry gives the median value of that particular statistic across the thirty stocks.

Turning to the results, the time series plot for $\operatorname{Corr}_{A A, X O N, t}$ in Figure 7 sugges ts important dependence and hence predictability in the correlations. This impression is confirmed by the correlogram in Figure 8 and the Ljung-Box portmanteau statistics for up to $22^{\text {nd }}$ order serial correlation reported in column 5 of Table $4 .^{22}$ Moreover, as with the ADF tests for $l v_{j, t}$, the tests for Corr $_{i, j, t}$ reported in the sixth column systematically reject the unit root hypothesis. Accordingly, the GPH estimates for $d$ are significantly different from zero (and unity), with typical values around 0.35 . The correspond ing hyperbolic decay rate for $\operatorname{Corr}_{A A, X O N, t}$ superimp osed in Figure 8 and the scaling law in Figure 9, in which we plot $\log \left(\operatorname{Var}\left[\operatorname{Corr}_{A A, X O N, t}\right]_{h}\right)$ against $\log (h)$, for $h=1,2, \ldots, 30$, also reveal highly

\footnotetext{
20 LeBaron (1999) has recently demonstrated that apparent sca ling laws may arise for short-memory, but highly persistent processes. In the present context, the hyperbolic decay in Figure 5 further buttresses the long-memory argument.

21 In a recent paper, C ampbell et al. (2000) arg ue that althou gh the number of stocks required to ach ieve a given level of diversification has increased noticeably over the past two decades, firm-specific volatility has also gone up, so that individual stock return correlations have actually decreased over the same time period.

22 As in Figure 5, the flat dashed line denotes the upper range of the ninety-five percent Bartlett confidence band.
} 
accurate fits.

Overall, our results thus far suggest that the univariate unconditional and conditional distributions for the realized correlations closely mimic the qua litative characteris tics of the realized volatilities discussed earlier. We now turn to multivariate a spects of the distributions, focusing first on is sues related to asymmetry in the distributions of the volatilities.

\section{Asymm etric Responses of Volatilities and Correlations}

A number of previous studies have documented an asymmetry in the relationship between equity volatility and returns, i.e., positive returns have a smaller impact on future volatility than negative returns of the same absolute magnitude. Two competing explanations have been put forth to rationalize this phenomenon. According to the so-called leverage effect, a large negative return increases financial and operating leverage, in turn raising equity return volatility (e.g., Black, 1976, and Christie, 1982). Alternatively, if the market risk premium is an increasing function of volatility, large negative returns increase the future volatility by more than positive returns due to a volatility feedback

effect (e.g., Campbell and Hentschel, 1992). We now re-evaluate the underlying empirical evidence on the basis of our realized volatility measures.

\subsection{Logarithmic Standard Deviations}

The use of realized volatilities allows for direct tests of asymmetries in the impact of past returns. However, in order to avoid confusing such effects with the strong serial correlation documented in the previous section, it is imperative that dynamic dependence be modeled properly. The first four columns in Table 5 report the regression estimates based on the fractionally differenced series,

$$
(1-L)^{d i} l v_{i, t}=\omega_{i}+\gamma_{i} \cdot l v_{i, t-1}+\phi_{i} \cdot l v_{i, t-1} I\left(r_{i, t-1}<0\right)+u_{i, t}
$$

where $I(\cdot)$ refers to the indicator function, and the values for $d_{i}$ are fixed at the $d_{G P H}$ estimates reported in Table 4. Also, to accomm odate any additional short-run dynamics, the t-statistics are based on a Newey-West robust covariance matrix estimator using 22 lags.

The median estimated value of $\gamma_{i}$ equals - 0.023 , and only one of the thirty t-statistics for $\gamma_{i}$ is statistically significantly greater than zero, when judged by the standard 95 -percent critical value of 
1.645. ${ }^{23}$ Simultaneously, the median estimate for $\phi_{i}$ equals 0.053 , and 22 of the thirty t-statistics exceed the five percent critical value. These results are broadly consistent with the EGARCH model estimates for daily individual stock returns reported by Cheung and $\mathrm{Ng}$ (1992) and Kim and Kon (1994), indicating a differential impact, or asymmetry, in the influence of past negative and positive returns.

However, although statistically significant for most of the stocks, the economic importance of this effect is marginal. Consider Figure 10, which displays the scatterplots for the logarithmic standard deviation for AA, $l v_{A A, t}$, against the lagged standardized returns, $r_{A A, t-1} / v_{A A, t-1}$. For visual reference, we have superimposed the two regression lines corresponding to negative and positive returns. This figure provides a direct analogy to the news impact curves for parametric ARCH models previously studied by Pagan and Schwert (1990) and Engle and Ng (1993). Although the news impact curve is more steeply sloped to the left of the origin, the systematic effect is obviously not very strong; similar plots for each of the 29 other stocks are available in ABDE (2000). This parallels the findings for the four individual stocks in Tauchen, Zhang and Liu (1996), who note that while asymmetry is a characteristic of the point estimates, the magnitude is quite small. In contrast, the parametric volatility model estimates reported in Nelson (1991), Glosten, Jagannathan and Runkle (1993) and Hentschel (1995), among others, all point tow ard important as ymmetries in market-w ide equity index returns, which calls into question the leverage explanation and instead suggests that the significant asymmetries for the aggregate market returns reported in these studies are most likely due to a volatility feedback effect (see also the recent discussion of Bekaert and $\mathrm{Wu}, 2000$ ).

\subsection{Correlations}

As noted above, little is known about the distributions of individual stock return correlations. If the volatility as ymme try at the individual stock level is cau sed by a leverage effect, then a change in financial leverage is likely to also affect the covariances between different stocks, which in turn may impact the correlations. In this regard it is interesting to note that the different multivariate ARCH models estimated in Kroner and $\mathrm{Ng}$ (1998) generally result in statistically signific ant as ymme tries in the conditional covariance matrices for the we ekly returns on a pair of well diversified small- and

\footnotetext{
${ }^{23}$ Note that, as long as $-\gamma_{i}<d_{i}$, a negative value for $\gamma_{i}$ is fully consistent with the strong volatility clustering effect documen ted above, a s a series expansion of the fractional differencing op erator in equation (5) would imply that terms of the form $d_{i} \cdot l v_{i, t-1}, 1 / 2 \cdot d_{i} \cdot\left(1-d_{i}\right) \cdot l v_{i, t-2}, \ldots$ also enter the right-hand-side in the corresponding equation for $l v_{i, t}$.
} 
large-stock portfolios. ${ }^{24}$ Similarly, Ang and Chen (2000) have recently demonstrated significant asymmetries in the correlations between the market and various industry, size, and book-to-market sorted portfolios. At the same time, the bivariate EGARCH models in Braun, Nelson and Sunier (1995) indicate that while the overall market volatility responds asymmetrically to positive and negative shocks, monthly conditional (time-varying) betas for size- and industry-sorted portfolios are mostly symmetric. More recently, however, Cho and Engle (1999) report statistically significant asymmetries in daily EGARCH betas for a small set of individual stocks, suggesting that the apparent symmetry in the monthly portfolio betas in Braun, Nelson and Sunier (1999) may be due to crosssectional and/or temporal aggregation effects.

In light of these findings, we now extend the analysis above to test for asymmetries in the realized daily correlations. In particular, the last three columns in Table 5 report the results from the regressions,

$$
\begin{gathered}
(1-L)^{d i, j} \operatorname{Corr}_{i, j, t}=\omega_{i, j}+\gamma_{i, j} \cdot\left(l v_{i, t-1}+l v_{j, t-1}\right)+\theta_{i, j} \cdot\left(l v_{i, t-1}+l v_{j, t-1}\right) \cdot I\left(r_{i, t-1} \cdot r_{j, t-1}>0\right) \\
\left.+\phi_{i, j} \cdot\left(l v_{i, t-1}+l v_{j, t-1}\right) \cdot I\left(r_{i, t-1}<0, r_{j, t-1}<0\right)\right\}+u_{i, j, t},
\end{gathered}
$$

where, as before, the $d_{i, j}$ are fixed at the $d_{G P H}$ estimates reported in Table 4, and the t-statistics are based on a Newey-West HAC covariance matrix estimator using 22 lags. Note that $\gamma_{i, j}$ captures the impact of the past realized volatilities on the correlations, $\theta_{i, j}$ gives the additional influence when the past returns are of the same sign, while the overall impact of the past volatility if both of the returns are negative is measured by $\gamma_{i, j}+\theta_{i, j}+\phi_{i, j}$. This particular formulation therefore facilitates a direct test of asymmetry based on the t-statistic for $\phi_{i, j}{ }^{25}$

Turning to the results, most of the 435 estimates for $\phi_{i, j}$ are indeed positive. However, less than half are significant at the usual 95-percent level when judged by the $t_{\phi}$-statistics. This relatively weak asymmetry is underscore d by Figure 11, which plots the daily realized correlations for AA and

\footnotetext{
24 In the context of international equity markets, Erb, Harvey and Viskanta (1994) and Longin and Solnik (1998) have also argued that the cross-country correlations tend to be higher when the returns are negative.

25 Because of the fractional differencing operator on the left side of the equation, the actual coefficient values should be carefully interpreted.
} 
$\mathrm{XON}, \operatorname{Corr}_{A A, X O N, t}$, against the average lagged standardized returns, $1 / 2 \cdot\left(r_{A A, t-1} / v_{A A, t-1}+r_{X O N, t-1} / v_{X O N, t-1}\right)$. As with the realized volatility news impact curve in Figure 10, the line corresponding to the sum of the two lagged returns being negative is slightly more steeply sloped than the line corresponding to the sum of the lagged returns being positive. How ever, the systematic influence of this effect is clearly not very important. Similar graphs obtain for all of the other stocks (see ABDE, 2000).

\section{Multivariate Unconditional Volatility Distributions}

Here we investigate various aspects of the multivariate unconditional volatility distributions. Many key economic and financial, as well as regulatory, questions depend upon the perceived commonality in volatility movements ac ross ass ets and markets. Most of the existing evidence concerning the extent of such co-movements relies on very specific parametric volatility models. The realized volatility measures, in contrast, allow for a direct assessment of the relationship between the individual standard deviations and correlations.

We begin in Figure 12 with a scatterplot of the realized daily logarithmic standard deviation of AA, $l v_{A A, t}$, against the logarithmic standard deviation of XON, $l v_{X O N, t}$. It is evident that the two volatilities move together. This feature als o holds for the other stocks. From the first column in Table 6 , the median corre lation between $l v_{i, t}$ and $l v_{j, t}$ acros s the 435 unique pairw ise combinations equals $0.205{ }^{26}$ As discussed further below, this tendency of return volatility to vary in tandem across individual stocks is consistent with factor structure, as in Diebold and Nerlove (1989), Tauchen and Tauchen (1999), and others.

Next, in Figure 13 and the second column of Table 6, we document the presence of what might be termed a volatility-in-correlation effect. In particular, in Figure 13 we plot the average realized daily correlations for AA, $(1 / 29) \cdot \Sigma_{i} \operatorname{Corr}_{A A, i, t}$ for $i \neq A A$, against the logarithmic standard deviation for AA, $l v_{A A, t}$. As for the foreign exchange rates analyzed in ABDL (1999a), a strong positive as sociation is evident. This is further unders cored by the results in the second column in Table 6. The median correlation between all of the individual correlations, $\operatorname{Corr}_{i, i, t}$, and the corresponding logarithmic standard deviations, $l v_{h, t}$ for $i=h$ or $j=h$, equals 0.150 . While similar

\footnotetext{
26 Embrechts, McNeil and Strauman (1999) have recently advocated the use of copulas and rank statistics when measuring dependence in non-normally distributed financial data. However, because the unconditional distributions that we explore in Table 6 are all approximately Gaussian, the linear correlation affords the most natural measure in the present context.
} 
volatility-in-correlation effects have been documented for other broadly defined market indexes, our direct model-free measurem ents of realized correlations and volatilities are very different from the procedures previously entertained in the literature, and as such our findings provide additional empirical support for the phenomenon. ${ }^{27}$ As shown below, a volatility effect in correlation is also to be expected within a factor structure, just as with the positive correlation across volatilities (see also Ronn, Sayrak, and Tompaidis, 1998). At the same time, the specific manifes tation of the effect is model dependent, which renders direct predictions about magnitudes impossible within our nonparametric setting. Nonetheless, the strength of the effect is noteworthy and provides a benchmark measure that candidate models should be able to accommodate. At the least, it suggests that standard mean-variance efficiency calculations based on constant correlations may be misguided.

Our final look at the multivariate volatility distributions in Figure 14 shows the scatter plot of average realized daily correlations for AA against the average realized correlations for XON; i.e., $(1 / 28) \cdot \Sigma_{i} \operatorname{Corr}_{A A, i, t}$ versus $(1 / 28) \cdot \Sigma_{i} \operatorname{Corr}_{X O N, i, t}$ for $i \neq A A$ and $i \neq X O N$. The strong association between the realized daily correlations is truly striking. Clearly, there is a powerful comm onality in the comovements across the individual stocks. The last column of Table 6 tells the same story. The smallest correlation among the $82,215(=30 \cdot 29 \cdot 28 \cdot 27 / 8)$ unique correlations is as high as 0.093 , and the median correlation between the daily time series of realized correlations equals 0.308 . Again, this seems to suggest that there is a lower dimensional factor structure driving the second moment characteristics of the joint distribution, to which we now turn.

\section{Latent Factor Structure in Volatility}

The notion of a low-dimensional factor structure is central to modern asset pricing theory (e.g., Cochrane, 2000). W e brie fly explore the properties of realized volatility in the context of a simple multivariate model with an explicit factor structure. We focus on three of the empirical results noted above: the tendency for volatilities to move together, the tendency for correlations to be high when the corresponding volatilities are high, and the tendency for an arbitrary correlation to be high when other correlations are also high.

\footnotetext{
${ }^{27}$ Similar observations have recently been made in the context of international equity index returns by Solnik, Boucrelle and Le Fur (1996). This also motivates the switching ARCH model estimated by Ramchand and Susmel (1998), who argue that the correlations between the U.S. and other world markets are on average 2 to 3.5 times higher when the U.S. market is in a high variance state as compared to a low variance state.
} 
Consider an $N$-dimensional diffusion for $\log$ price $p_{t}$ with the single-factor repres entation

$$
d p_{t}=\lambda \sigma_{t} d W_{t}+\Omega d V_{t}
$$

where $\lambda$ is an $N$-dimensional vector of loadings on the common volatility factor $\sigma_{t} d W_{t}, V_{t}$ is an $N$ dimensional stand ard B rownian motion with mutually-ind ependent elements, and the diag onal ma trix $\Omega$ contains $N$ individual asset-specific volatilities. Note that each element of the $\mathrm{N}$-vector of returns $d p_{t}$ is driven in part by a single latent factor with stochastic volatility, and in part by an orthogonal idiosyncratic noise.

Given the simple model (7), the $N$-dimensional vect or of daily returns is

$$
r_{t+1} \equiv p_{t+1}-p_{t}=\int \lambda \sigma_{t} d W_{t}+\int \Omega d V_{t}
$$

Letting $\Sigma_{t}$ denote the corresp onding $N \times N$ covariance matrix conditional on the sample path filtration generated by the latent volatility process, $\left\{\sigma_{t+\tau}\right\}_{\tau=0}^{\mathbf{1}}$, the element of $\Sigma_{t}$ corresponding to the covariance between the $i$ th and $j$ th elements of $r_{t+1}$, say $\left\{r_{t+1}\right\}_{i}$ and $\left\{r_{t+1}\right\}_{j}$, is

$$
\left\{\Sigma_{t}\right\}_{i, j} \equiv\left\{\lambda \lambda^{\prime}\right\}_{i, j} \int \sigma_{t+\tau}^{2} d \tau+\Omega_{i j}
$$

Hence, the conditional variances and covariances inherit their dynamics from $\sigma_{t}$, a fact with important implications for comovements among volatilities and correlations.

In order to relate this factor model directly to daily realized volatilities and corre lations, it is convenient to restate the system in discrete time. The continuous-time latent factor volatility model (7)(9) map s directly into a discrete-time model that has been studied by a number of authors, including Diebold and Nerlove (1989), Harvey, Ruiz and Shephard (1994), King, Sentana and Wadhw ani (1994), Fiorentini, Sentana and Shephard (1998), and Jacquier and Marcus (2000):

$$
\begin{aligned}
& r_{i t}=\lambda_{i} f_{t}+v_{i t} \\
& f_{t} \mid I_{t} \sim\left(0, h_{t}\right)
\end{aligned}
$$




$$
\begin{aligned}
& \stackrel{i i d}{\sim}\left(0, \omega_{i}^{2}\right) \\
& \operatorname{cov}\left(v_{i t} v_{j t}\right)=0, \forall i \neq j, t \neq t^{\prime},
\end{aligned}
$$

where $i, j=1, \ldots, N$, and $t=1, \ldots, T$.

It is readily established that volatilities tend to move together in such a factor model. Concretely, the $i^{\text {th }}$ and $j^{\text {th }}$ time-t conditional variances, for arbitrary $i$ and $j$, are

$$
\begin{aligned}
& h_{i t}=\lambda_{i}^{2} h_{t}+\omega_{i}^{2} \\
& h_{j t}=\lambda_{j}^{2} h_{t}+\omega_{j}^{2} .
\end{aligned}
$$

Note in particular that the conditional variances, which are them selves covariance stationary stochastic processes, are linear functions of latent volatility $\boldsymbol{h}_{\boldsymbol{t}}$ and are the refore driven entirely by movements in volatility. The unconditional covariance between $\boldsymbol{h}_{\boldsymbol{i t}}$ and $\boldsymbol{h}_{\boldsymbol{j} t}$ is

$$
\operatorname{cov}\left(h_{i t} h_{j t}\right)=E_{[}\left(\lambda_{i}^{2} h_{t}+\omega_{i}^{2}\right)-\left(\lambda_{i}^{2} E\left(h_{t}\right)+\omega_{i}^{2}\right)_{j}\left(\lambda_{j}^{2} h_{t}+\omega_{j}^{2}\right)-\left(\lambda_{j}^{2} E\left(h_{t}\right)+\omega_{j}^{2}\right)_{]}=\lambda_{i}^{2} \lambda_{j}^{2}\left(h_{t}-E\left(h_{t}\right)\right)^{2},
$$

which is unambiguou sly positive. Hence the unconditional correlation between $\boldsymbol{h}_{\boldsymbol{i t}}$ and $\boldsymbol{h}_{\boldsymbol{j} \boldsymbol{t}}$ is also unambiguously positive.

It is also readily seen why a factor structure induces high correlations in situations of high volatility. The $\mathrm{ij}^{\text {th }}$ time- $\mathrm{t}$ conditional covariance is

$$
\operatorname{cov}_{i j t}=\lambda_{i} \lambda_{j} h_{t}
$$

so the conditional correlation is

$$
\operatorname{corr}_{i j t}=\frac{\lambda_{i} \lambda_{j} h_{t}}{\sqrt{\lambda_{i}^{2} h_{t}+\omega_{i}^{2}} \sqrt{\lambda_{j}^{2} h_{t}+\omega_{j}^{2}}} .
$$


Note the conditional variance effect in conditional correlation: if $\lambda_{i}, \lambda_{j}, h_{t}>0$, then

$\frac{\partial \operatorname{corr}_{i j t}}{\partial h_{t}}>0$. Moreover, $\lim _{h_{t} \rightarrow \infty} \operatorname{corr}_{i j t}=1$ and $\lim _{h_{t} \rightarrow 0} \operatorname{corr}_{i j t}=0$.

Finally, it is straightforward to verify that a factor structure implies that if the correlation between an arbitrary pair of stocks is high, the correlations between other stocks tend to be high also. In fact, equation (14) makes clear that, so long as all stocks load positively off the common factor, all pairwise corre lations are increasing in volatility. Hence, as volatility moves, the pairwise correlations all move as well, and in the same direction.

In closing, we note that it is easy to extend these results to richer factor structures, including models with dynamics in $\Omega$ and models with multiple factors, as in recent work by Lo and Wang (2000) on modeling volume, which is intimately related to the modeling of volatility.

\section{Conclusions}

We exploit direct model-free measures of realized daily volatility and correlation obtained from highfrequency intraday stock prices to confirm, solidify and extend existing characterizations. Our findings are remarkably consistent with exis ting work such as ABDL (1999a, b) and Ebens (1999a). This is true of the right-skewed distributions of the variances and covariances, the normal distributions of the logarithmic standard deviations and correlations, the normal distributions of daily returns standardized by realized standard deviations, and the strongly persistent dynamics of the realized volatilities and correlations, well-described by a stationary fractionally integrated process and conforming to scaling laws under temporal aggregation. The striking congruence of all findings across asset classes (equity vs. for ex) and underlying method of price recording (trans action prices vs. averages of logarithmic bid and ask quotes) suggests that the results reflect fundamental attributes of speculative returns.

Our analysis is noteworthy not only for confirming and checking robustness of existing results, but also for achieving significant extensions, facilitated throughout by the model-free measurem ent of realized volatility and correlation afforded by high-frequency data, and the simplicity of our methods, which enable straightforward high-dimensional correlation estimation. We shed new light on some distinct properties of equity return dynamics and illustrate them, for example, via the news impact curve. We confirm the existence of an asymmetric relation between returns and volatility, with 
negative returns being associated with higher volatility innovations than positive returns of the same magnitude. However, the effect is much weaker at the individual stock level than at the aggregate market level, thus lending support to a volatility risk premium feedback explanation rather than a financial leverage effect. Moreover, we find a pronounced volatility-in-correlation effect, thus limiting the benefits of portfolio diversification when they are needed most. The strength of this relation suggests that suboptimal decisions will result from analysis based on the premise of a constant or fixed variance-covariance structure. Finally, the volatility-in-correlation effect, the strong positive association between individual stock volatilities, and the corresponding strong relationship between contemporaneous stock correlations should motivate additional work on the development of parsimonious factor models for the covariance structure of stock returns.

We envision several applications of the approach adopted in this paper. For example, the direct measurement of volatilities and correlations should alleviate the errors-in-variables problem that plagues much work on the implementation and testing of the CAPM, because realized betas may be constructed directly from the corresponding realized covariances and standard deviations. Multi-factor models based on factor replicating portfolios are similarly amenable to direct analysis. As a second example, the effective observability of volatilities and correlations facilitates direct time-series modeling of portfolio choice and risk management problems under realistic and testable distributional assumptions. Work along these lines is currently being pursued in Anders en, Bollerslev, Diebold and Labys (1999d). Finally, our methods will also facilitate direct comparisons of volatility forecasts generated by alternative models and procedures. Such explorations are underway in Ebens (1999b) and Ebens and de Lima (1999). 


\section{References}

Andersen, T.G. (1996), "Return Volatility and Trading Volume: An Information Flow Interp retation of Stochastic Volatility," Journal of Finance, 51, 169-204.

Andersen, T.G. and T. Bollerslev (1997), "Heterogeneous Information Arrivals and Return Volatility Dynamics: Uncovering the Long-Run in High Frequency Returns," Journal of Finance, 52, 975-1005.

Andersen, T.G. and T. Bollers lev (1998), "Answering the Skeptics: Yes, Standard Volatility Models do Provide Accurate Forecasts," International Economic Review, 39, 885-905.

Andersen, T.G., T. Bollerslev, and A. Das (2000), "V ariance Ratios and High-Frequency Data: Testing for Changes in Intraday Volatility Patterns," Journal of Finance, forthcoming.

Andersen, T.G., T. Bollerslev, F.X. Diebold and H. Ebens (2000), "The Distribution of Stock Return Volatility: Appendix,” Manuscript, Northwestern University, Duke University, New York University and Johns Hopkins University.

Andersen, T.G., T. Bollerslev, F.X. Diebold and P. Labys (1999a), "Exchange Rate Returns Standardized by Realized Volatility are (Nearly) Gaussian,” NBER Working Paper No. 7488.

Andersen, T.G., T. Bollerslev, F.X. Diebold and P. Labys (1999b), "Microstructure Bias and Volatility Signatures," work in progress.

Andersen, T.G., T. Bollerslev, F.X. Diebold and P. Labys (1999c), "Forecasting Volatility: A VAR for VaR," work in progress.

Andersen, T.G., T. Bollerslev, F.X. Diebold and P. Labys (2000), "The Distribution of Exchange Rate Volatility," Revised version of NBER Working Paper No. 6961.

Ang, A. and J. Chen (2000), "A symmetric Correlations of Equity Portfolios," Manuscript, Grad uate School of Business, Columb ia University.

Back, K. (1991), “Asset Prices for General Processes,” Journal of Mathematical Economics, 20, 317 395.

Baillie, R.T., T. Bollerslev and H.O. Mikkelsen (1996), "Fractionally Integrated Generalized Autoregressive Conditional Heteroskedasticity," Journal of Econometrics, 74, 3-30.

Bekaert, G. and G. Wu (2000), “Asymmetric Volatility and Risk in Equity Markets," Review of Financial Studies, 13, 1-42.

Black, F. (1976), "Studies of Stock Market Volatility Changes," Proceedings of the American Statistical Association, Business and Economic Statistics Section, 177-181. 
Blattberg, R.C. and N.J. Gonedes (1974), "Comparison of the Stable and Student Distributions as Statistical Models for Stock Prices," Journal of Business, 47, 244-280.

Bollerslev, T., R. Y. Chou and K.F. Kroner (1992), “ARCH Modeling in Finance: A Selective Review of the Theory and Empirical Evidence," Journal of Econometrics, 52, 5-59.

Bollerslev, T., R.F. Engle and D.B. Nelson (1994), "ARCH Models," in R.F. Engle and D. McFadden (eds.), Handbook of Econometrics, Volume IV, 2959-3038. Amsterdam: North-Holland.

Bollerslev, T. and H.O. Mikkelsen (1999), "Long-Term Equity Anticipation Securities and Stock Market Volatility Dynamics," Journal of Econometrics, 92, 75-99.

Braun, P.A., D.B. Nelson and A.M. Sunier (1995), "Good News, B ad News, Volatility and Betas," Journal of Finance, 50, 1575-1603.

Breidt, F.J., N. Crato, and P. de Lima (1998), "On the Detection and Estimation of Long-Memory in Stochastic Volatility," Journal of Econometrics, 83, 325-348.

Campbell, J.Y. and L. Hentschel (1992), "No News is Good News: An Asymmetric Model of Changing Volatility in Stock Returns," Journal of Financial Economics, 31, 281-318.

Campbell, J.Y., M. Lettau, B.G. Malkiel and Y. Xu (2000), "Have Individual Stocks Become More Volatile? An Empirical Exploration of Idiosyncratic Risk," Journal of Finance, forthcoming.

Campbell, J.Y., A.W. Lo. and A.C. MacKinlay (1997), The Economics of Financial Markets. Princeton: Princeton University Press.

Canina, L. and S. Figlewski (1993), "The Informational Content of Implied Volatility," Review of Financial Studies, 6, 659-681.

Cheung, Y.-W. and L. Ng (1992), "Stock Price Dynamics and Firm Size: An Empirical Investigation," Journal of Finance, 47, 1985-1997.

Cho, Y.H. and R.F. Engle (1999), "Time-Varying Betas and Asymmetric Effects of News: Empirical Analysis of Blue Chip Stocks,” NBER Working Paper No.7330.

Christensen, B.J. and N.R. Prabhala (1998), "The Relation Between Implied and Realized Volatility," Journal of Financial Economics, 50, 125-150.

Christie, A.A. (1982), "The Stochastic Behavior of Common Stock Variances: Value, Leverage and Interest Rate Effects," Journal of Financial Economics, 10, 407-432.

Clark, P. K. (1973), “A Subordinated Stochastic Process Model with Finite Variance for Speculative Prices," Econometrica, 41, 135-155.

Cochrane, J.H. (2000), Asset Pricing. Manuscript, University of Chicago. 
Crato, N. and P.J. de Lima (1993), "Long-Range Dependence in the Conditional Variance of Stock Returns," Economics Letters, 25, 281-285.

Day, T.E. and C.M. Lewis (1992), "Stock Market Volatility and the Information Content of Stock Index Options," Journal of Econometrics, 52, 267-287.

Deo, R.S. and C.M. Hurvich (1999), "On the Log-Periodogram Regression Estimator of the Memory Parameter in Long-Memory Stochastic Volatility Models,” Manus cript, New Y ork University.

Diebold, F.X. and M. Nerlove (1989), "The Dynamics of Exchange Rate Volatility: A Multivariate Latent Factor ARCH Model," Journal of Applied Econometrics, 4, 1-22.

Ding, Z., C.W .J. Granger and R.F. Engle (1993), “A Long Memory Property of Stock Market Returns and a New Model," Journal of Empirical Finance, 1, 83-106.

Duffee, G.R. (1995), "Stock Returns and Volatility: A Firm Level Analysis," Journal of Financial Analysis, 37, 399420.

Drost, F.C., T.E. Nijman and B.J.M. Werker (1998), "Estimation and Testing in Models Containing Both Jumps and Conditional Heteroskedasticity," Journal of Business and Economic Statistics, 16, 237-243.

Ebens, H. (1999a), “Realized S tock Index Volatility,” Working Paper No. 420, Department of Econ omics, Johns Hopkins Univer sity.

Ebens, H. (1999b), "Forecasting Stock Volatility," work in progress.

Ebens, H. and P. de Lima (1999), "The Volatility Implied by Options and Realized Volatility,” work in progress.

Embrechts, P., A. McNeil and D. Straumann (1999), "Correlation and Dependency in Risk Management: Properties and Pitfalls,” Manuscript, ETH Zürich, Switzerland.

Engle, R.F. and G.G.J. Lee (1993), "Long Run Volatility Forecasting for Individual Stocks in a One Factor Model," Manus cript, University of California, San Diego.

Engle, R.F. and V.K. Ng (1993), "Measuring and Testing the Impact of News on Volatility," Journal of Finance, 48, 1749-1778.

Erb, C.B., C.R. Harvey and T.E. Viskanta (1994), "Forecasting International Equity Correlations," Financial Analysts Journal, November/December, 32-45.

Fama, E.F. (1965), “The Behavior of Stock Market Prices,” Journal of Business, 38, 34-105.

Fiorentini, G., E. Sentana and N. Shephard (1998), "Exact Likelihood-Based Estimation of Conditionally Heteroskedastic Factor Models," Manus cript, University of Alcante, CEMFI and Ox ford University. 
French, K.R., G.W. Schwert and R.F. Stamb augh (1987), "Expected Stock Returns and Volatility," Journal of Financial Economics, 19, 3-29.

Fung, W.K.H. and D.A. Hsieh (1991), "Empirical Analysis of Implied Volatility: Stocks, Bond s and Currencies," Manuscript, Duke University.

Gallant, A.R., P.E. Rossi and G.E. Tauchen (1992), "Stock Prices and Volume," Review of Financial Studies, 5, 199-242.

Geweke, J. and S. Porter-Hudak (1983), "The Estimation and Application of Long Memory Time Series Models," Journal of Time Series Analysis, 4, 221-238.

Glosten, L.R., R. Jagannathan and D.E. Runkle (1993), "On the Relation Between the Expected Value and the Volatility of the Nominal Excess Return on Stocks," Journal of Finance, 48, 17791801 .

Harvey, A., E. Ruiz and N. Shephard (1994), "Multivariate Stochastic Variance Models," Review of Economic Studies, 61, 247-264.

Hentschel, L. (1995), "All in the Family: Nesting Symmetric and Asymmetric GARCH Models," Journal of Financial Economics, 39, 71-104.

Hsieh, D.A. (1991), "Chaos and Nonlinear Dynamics: Application to Financial Markets," Journal of Finance, 46, 1839-1877.

Hull, J. and A. White (1987), "The Pricing of Options on Assets with Stochastic Volatilities," Journal of Finance, 42, 381-400.

Jacquier, E., N.G. Polson and P.E. Rossi (1994), "Bayesian Analysis of Stochastic Volatility Models," Journal of Business and Economic Statistics, 12, 371-417.

Jacquier, E. and A.J. Marcus (2000), "Market Volatility and Asset Correlation Structure,” Manuscript, Boston College.

Kim, D. and S.J. Kon (1994), “Alternative Models for the Conditional Heteroskedasticity of Stock Returns," Journal of Business, 67, 563-598.

King, M., E. Sentana and S. Wadhwani (1994), "Volatility and Links Between National Stock Markets," Econometrica, 62, 901-933.

Kroner, K.F. and V.K. Ng (1998), "Modeling Asymmetric Comovements of Asset Returns," Review of Financial Studies, 11, 817-844.

Kuwahara, H. and T.A. Marsh (1992), “The Pricing of Japanese Equity Warrants,” Management Science, 38, 1610-1641. 
Lamoureux, C.G. and W.D. Lastrapes (1990), "Heteroskedasticity in Stock Retum Data: Volume versus GARCH Effects," Journal of Finance, 45, 221-229.

Lamoureux, C.G. and W.D. Lastrapes (1993), "Forecasting Stock Returns Variances: Towards Understanding Stochastic Implied Volatility,” Review of Financial Studies, 6, 293-326.

LeBaron, B. (1999), "Volatility Persistence and Apparent Scaling Laws in Finance," Manuscript, Brande is University.

Ledoit, O. and P. Santa-Clara (1998), "Relative Pricing of Options with Stochastic Volatility," Manuscript, UCLA.

Lo, A.W. and J. Wang (2000), "Trading Volume: Definitions, Data Analysis, and Implications of Portfolio Theory," Review of Financial Studies, 13, 257-300.

Longin, F. and B. Solnik (1998), "Correlation Structure of International Equity Markets During Extremely Volatile Periods," ESSEC Graduate Business School and HEC School of Management.

Mandelbrot, B. (1963), "The Variation of Certain Speculative Prices,” Journal of Business, 36, 394419.

Merton, R.C. (1980), “On Estimating the Expected Return on the Market," Journal of Financial Economics, 8, 323-361.

Nelson, D.B. (1990), “ARCH Models as Diffusion Approximations,” Journal of Econometrics, 45, 738.

Nelson, D.B. (1991), "Conditional Heteroskedasticity in Asset Returns: A New Approach," Econometrica, 59, 347-370.

Nelson, D.B . (1992), "Filtering and Forecasting with Misspecified ARCH Models I: Getting the Right Variance with the Wrong Model," Journal of Econometrics, 52, 61-90.

Nelson, D.B. and D.P. Foster (1994), "Asymptotic Filtering Theory for Univariate ARCH Models," Econometrica, 62, 1-41.

Pagan, A.R. and G.W. Schwert (1990), “Alternative Models for Conditional Stock Volatility,” Journal of Econometrics, 45, 267-290.

Praetz, P.D. (1972), “The Distribution of Share Price Changes,” Journal of Business, 45, 49-55.

Protter, P. (1992). Stochastic Integration and Differential Equations. New York: Springer Verlag.

Ramchand, L. and R. Susmel (1998), "Volatility and Cross Correlation Across Major Stock Markets," Journal of Empirical Finance, 5, 397-416. 
Robinson, P.M. (1995), "Log-Periodogram Regres sion of Time Series with Long-Range Dependence," Annals of Statistic, 23, 1048-1072.

Robinson, P.M. and P. Zaffaroni (1998), "Nonlinear Time Series with Long Memory: A Model for Stochastic Volatility," Journal of Statistical Planning and Inference, 68, 359-371.

Ronn, E.I., A. Sayrak and S. Tompaidis (1999), "The Impact of Large Changes in Ass et Prices on Intra-Market Correlations in the Stock, Bond, and International Markets," Manuscript, University of Texas at Austin.

Schw ert, G.W . (1987), "Effects of Model Specification on Tests for Unit Roots in Macroeconomic Data," Journal of Monetary Economics, 20, 73-103.

Schwert, G.W. (1989), "Why Does Stock Market Volatility Change Over Time?," Journal of Finance, 44, 1115-1153.

Schwert, G.W. (1990a), “Stock Market Volatility,” Financial Analysts Journal, May-June, 23-34.

Schwert, G.W. (1990b), "Stock Volatility and the Crash of '87," Review of Financial Studies, 3, 77102.

Schwert, G.W. and P.J. Seguin (1991), "Heteroskedasticity in Stock Returns," Journal of Finance, 45, 1129-1155.

Silverman, B.W. (1986). Density Estimation. Lond on, UK: Chapman and Hall.

Solnik, B., C. Boucrelle and Y. Le Fur (1996), "International Market Correlation and Volatility," Financial Analysts Journal, September-October, 17-34.

Tauchen, G.E. and H. Tauchen (1999), "The Volatility Structure of the Dow," work in progress.

Tauchen, G.E., H. Zhang and M. Liu (1996), "Volume, Volatility and Leverage: A D ynamic Analysis," Journal of Econometrics, 74, 177-208.

Taylor, S.J. (1986), Modeling Financial Time Series. Chichester, Great Britain: John Wiley \& Sons.

Zumbach, G.O., M.M. Dacorogna, J.L. Olsen and R.B. Olsen (1999), "Introducing a Scale of Market Shocks," Manuscript, Olsen and Associates, Zurich. 
Table 1

Unconditional Daily Return Distributions

\begin{tabular}{|c|c|c|c|c|c|c|c|}
\hline \multirow[b]{2}{*}{ Stock } & \multicolumn{4}{|c|}{$r_{i, t}$} & \multicolumn{3}{|c|}{$r_{i, t} / v_{i, t}$} \\
\hline & Mean & St.Dev. & Skew. & Kurt. & Mean & St.Dev. & Skew. \\
\hline Min. & -0.059 & 1.149 & -0.221 & 3.810 & -0.033 & 0.623 & -0.054 \\
\hline 0.10 & -0.024 & 1.222 & -0.022 & 3.964 & -0.013 & 0.697 & 0.037 \\
\hline 0.25 & 0.007 & 1.275 & 0.035 & 4.236 & 0.002 & 0.772 & 0.081 \\
\hline 0.50 & 0.041 & 1.419 & 0.159 & 5.416 & 0.024 & 0.806 & 0.113 \\
\hline 0.75 & 0.071 & 1.538 & 0.231 & 6.587 & 0.048 & 0.852 & 0.164 \\
\hline 0.90 & 0.084 & 1.704 & 0.487 & 8.462 & 0.060 & 0.928 & 0.228 \\
\hline Max. & 0.140 & 1.833 & 0.564 & 11.98 & 0.099 & 0.960 & 0.322 \\
\hline Mean & 0.036 & 1.438 & 0.172 & 5.908 & 0.025 & 0.808 & 0.125 \\
\hline St.Dev. & 0.046 & 0.181 & 0.192 & 2.016 & 0.030 & 0.080 & 0.081 \\
\hline
\end{tabular}

Note: The table summarizes the daily return distributions for the 30 DJIA stocks, $r_{i, t}$. The sample covers the period from January 2, 1993 through May 29, 1998, for a total of 1,366 observations. The realized daily volatilities, $v_{i, t}$, are calculated from five-minute intraday returns, as detailed in the main text.

Table 2

Unconditional Daily Volatility Distributions

\begin{tabular}{|c|c|c|c|c|c|c|c|}
\hline \multirow[b]{2}{*}{ Stock } & \multicolumn{4}{|c|}{$v_{j, t}^{2}$} & \multicolumn{3}{|c|}{$l v_{i, t}$} \\
\hline & Mean & St.Dev. & Skew. & Kurt. & Mean & St.Dev. & Skew. \\
\hline Min. & 1.899 & 1.159 & 1.451 & 5.789 & 0.239 & 0.225 & -0.537 \\
\hline 0.10 & 2.009 & 1.348 & 2.306 & 11.98 & 0.280 & 0.228 & -0.308 \\
\hline 0.25 & 2.539 & 1.665 & 3.516 & 27.84 & 0.403 & 0.238 & -0.015 \\
\hline 0.50 & 3.108 & 1.988 & 5.609 & 66.16 & 0.476 & 0.264 & 0.192 \\
\hline 0.75 & 3.390 & 2.458 & 8.322 & 142.6 & 0.544 & 0.280 & 0.465 \\
\hline 0.90 & 4.315 & 4.346 & 18.89 & 518.0 & 0.664 & 0.294 & 0.777 \\
\hline Max. & 6.854 & 6.319 & 20.70 & 567.8 & 0.894 & 0.353 & 1.023 \\
\hline Mean & 3.178 & 2.355 & 7.433 & 143.6 & 0.478 & 0.263 & 0.222 \\
\hline St.Dev. & 1.146 & 1.203 & 5.664 & 176.8 & 0.150 & 0.029 & 0.388 \\
\hline
\end{tabular}

Note: The table summarizes the distributions of the daily volatilities for the 30 DJIA stocks. The realized daily variances, $v_{j, t}^{2}$, and logarithmic standard deviations, $l v_{i, t} \equiv \log \left(v_{i, t}\right)$, are calculated from five-minute intraday returns as detailed in the main text. 
Table 3

Unconditional Daily Covariance and Correlation Distributions

\begin{tabular}{|c|c|c|c|c|c|c|c|}
\hline \multirow[b]{2}{*}{ Stock } & \multicolumn{4}{|c|}{$\operatorname{Cov}_{i, j, t}$} & \multicolumn{3}{|c|}{$\operatorname{Corr}_{i, j, t}$} \\
\hline & Mean & St.Dev. & Skew. & Kurt. & Mean & St.Dev. & Skew. \\
\hline Min. & 0.217 & 0.362 & -4.714 & 8.411 & 0.062 & 0.128 & 0.008 \\
\hline 0.10 & 0.284 & 0.508 & 2.843 & 22.49 & 0.085 & 0.138 & 0.123 \\
\hline 0.25 & 0.318 & 0.580 & 3.738 & 33.97 & 0.098 & 0.142 & 0.180 \\
\hline 0.50 & 0.372 & 0.695 & 5.223 & 61.86 & 0.117 & 0.149 & 0.253 \\
\hline 0.75 & 0.426 & 0.819 & 7.704 & 120.6 & 0.136 & 0.157 & 0.312 \\
\hline 0.90 & 0.492 & 0.968 & 12.21 & 258.3 & 0.159 & 0.167 & 0.381 \\
\hline Max. & 0.697 & 1.899 & 24.91 & 773.4 & 0.221 & 0.196 & 0.568 \\
\hline Mean & 0.379 & 0.727 & 6.462 & 108.1 & 0.120 & 0.151 & 0.251 \\
\hline St.Dev. & 0.081 & 0.206 & 4.195 & 125.4 & 0.029 & 0.012 & 0.099 \\
\hline
\end{tabular}

Note: The table summarizes the distributions of the $435(=30 \cdot 29 / 2)$ unique realized covariances and correlations for the 30 DJIA stocks. The realized daily covariances and correlations are calculated from five-minute intraday returns, as detailed in the main text.

Table 4

Dynamic Volatility Dependence

\begin{tabular}{|c|c|c|c|c|c|c|c|}
\hline \multirow[b]{2}{*}{ Stock } & \multicolumn{4}{|c|}{$l v_{i, t}$} & \multicolumn{3}{|c|}{$\operatorname{Corr}_{i, j, t}$} \\
\hline & $Q_{22}$ & $A D F$ & $d_{G P H}$ & $d_{S}$ & $Q_{22}$ & $A D F$ & $d_{G P H}$ \\
\hline Min. & 982 & -4.850 & 0.263 & 0.286 & 155 & -5.351 & 0.117 \\
\hline 0.10 & 2080 & -4.466 & 0.284 & 0.334 & 395 & -4.566 & 0.278 \\
\hline 0.25 & 2966 & -3.918 & 0.317 & 0.359 & 660 & -4.065 & 0.326 \\
\hline 0.50 & 4715 & -3.327 & 0.349 & 0.386 & 1169 & -3.542 & 0.380 \\
\hline 0.75 & 6075 & -2.992 & 0.392 & 0.400 & 2167 & -2.983 & 0.439 \\
\hline 0.90 & 6921 & -2.676 & 0.409 & 0.412 & 3431 & -2.571 & 0.486 \\
\hline Max. & 14254 & -2.178 & 0.416 & 0.463 & 7209 & -1.917 & 0.600 \\
\hline Mean & 4729 & -3.450 & 0.350 & 0.377 & 1267 & -3.548 & 0.381 \\
\hline St.Dev. & 2556 & 0.665 & 0.046 & 0.038 & 1267 & 0.746 & 0.081 \\
\hline
\end{tabular}

Note: The table summarizes the time series dependence in the 30 realized logarithmic standard deviations and 435 realized correlations for the DJIA stocks. The table reports the Ljung-Box portmanteau test for up to 22 nd order autocorrelation, $Q_{22}$, the Augmented Dickey-Fuller test for a unit root involving 22 augmentation lags, $A D F$, the Geweke-Porter-Hudak estimate for the degree of fractional integration, $d_{G P H}$, and the estimate for the degree of fractional integration based on the scaling-law, $d_{S}$. 
Table 5

News Impact F unctions

\begin{tabular}{|c|c|c|c|c|c|c|c|}
\hline \multirow[b]{2}{*}{ Stock } & \multicolumn{4}{|c|}{$l v_{i, t}$} & \multicolumn{3}{|c|}{$\operatorname{Corr}_{i, j, t}$} \\
\hline & $\gamma$ & $t_{\gamma}$ & $\phi$ & $t_{\phi}$ & $t_{\gamma}$ & $t_{\theta}$ & $t_{\phi}$ \\
\hline Min. & -0.092 & -4.098 & 0.007 & 0.236 & -5.198 & -2.060 & -1.299 \\
\hline 0.10 & -0.067 & -2.930 & 0.022 & 0.908 & -3.015 & -0.911 & 0.162 \\
\hline 0.25 & -0.049 & -1.737 & 0.028 & 1.224 & -2.451 & -0.288 & 0.840 \\
\hline 0.50 & -0.023 & -0.754 & 0.053 & 2.277 & -1.660 & 0.333 & 1.406 \\
\hline 0.75 & 0.000 & 0.008 & 0.067 & 2.874 & -0.929 & 1.051 & 2.061 \\
\hline 0.90 & 0.026 & 1.039 & 0.081 & 3.753 & -0.118 & 1.646 & 2.815 \\
\hline Max. & 0.051 & 1.833 & 0.130 & 4.314 & 2.444 & 3.727 & 4.395 \\
\hline Mean & -0.021 & -0.825 & 0.051 & 2.246 & -1.636 & 0.387 & 1.450 \\
\hline St.Dev. & 0.035 & 1.455 & 0.027 & 1.067 & 1.180 & 0.988 & 1.026 \\
\hline
\end{tabular}

Note: The table reports the OLS regression estimates for the news impact functions for the fractionally differenced logarithmic standard deviations, $(1-L)^{d i} l v_{i, t}=\omega_{i}+\gamma_{i} l v_{i, t-1}+\phi_{i} \cdot l v_{i, t-1} \cdot I\left(r_{i, t-1}<0\right)+u_{i, t}$, and correlations, $(1-L)^{d i, j} \operatorname{Corr}_{i, j, t}=\omega_{i, j}+\gamma_{i, j} \cdot\left(l v_{i, t-1}+l v_{j, t-1}\right)+\theta_{i, j}\left(l v_{i, t-1}+l v_{j, t-1}\right) \cdot I\left(r_{i, t-1} \cdot r_{j, t-1}>0\right)+\phi_{i, j}\left(l v_{i, t-1}+l v_{j, t-}\right.$ $\left.\left.{ }_{l}\right) \cdot I\left(r_{i, t-1}<0, r_{j, t-1}<0\right)\right\}+u_{i, j, t}$, where the values for $d_{i}$ and $d_{i, j}$ are fixed at the $d_{G P H}$ estimates reported in Table 4. The $\mathrm{t}$-statistics are based on a Newey-West HAC covariance matrix estimator with 22 lags.

Table 6

Multivariate Unconditional Volatility Distributions

\begin{tabular}{|c|c|c|c|}
\hline Stock & $\operatorname{Corr}\left(l v_{i, t}, l v_{j, t}\right)$ & $\operatorname{Corr}\left(\operatorname{Corr}_{i, j, t}, l v_{i, t}\right)$ & $\operatorname{Corr}\left(\operatorname{Corr}_{i, j, t}, \operatorname{Corr}_{h, k, t}\right)$ \\
\hline Min & -0.327 & -0.209 & 0.093 \\
\hline 0.10 & -0.016 & -0.086 & 0.230 \\
\hline 0.25 & 0.081 & 0.032 & 0.265 \\
\hline 0.50 & 0.205 & 0.150 & 0.308 \\
\hline 0.75 & 0.321 & 0.236 & 0.358 \\
\hline 0.90 & 0.439 & 0.296 & 0.407 \\
\hline Max. & 0.641 & 0.536 & 0.601 \\
\hline Mean & 0.206 & 0.130 & 0.314 \\
\hline St.Dev. & 0.172 & 0.148 & 0.069 \\
\hline
\end{tabular}

Note: The column labeled $\operatorname{Corr}\left(l v_{i, t}, l v_{j, t}\right)$ gives the distribution of the $435(=30 \cdot 29 / 2)$ unique correlations between the 30 daily realized logarithmic volatilities for the DJIA stocks. The second column, Corr( $\left.\operatorname{Corr}_{i, j, t}, l v_{i, t}\right)$, refers to the distribution of the $870(=30 \cdot 29)$ unique correlations between the daily realized correlations and the corresponding logarithmic standard deviations. The last column denoted $\operatorname{Corr}_{\left(\operatorname{Corr}_{i, j, t}\right.}$ , Cor $\left._{h, k, t}\right)$ gives the distribution of the $82,215(=30 \cdot 29 \cdot 28 \cdot 27 / 8)$ unique correlations between the realized daily correlations. 


\section{Figure Titles and Notes}

\section{Figure 1}

Unconditional Distribution of Daily Standardized Returns

The figure shows the unconditional distributions of the standardized daily returns on AA, $r_{A A, t} / v_{A A, t}$. The sample period extends from January 2, 1993 through May 29, 1998, for a total of 1,366 daily observations. The realized volatilities are calculated from five-minute intra day returns. The dotted line refers to the standard normal density.

\section{Figure 2}

Unconditional Distribution of Standardized Daily Logarithmic Standard Deviations

The figure shows the unconditional distribution of the standardized daily realized logarithmic standard deviations for AA, $l v_{A A, t} \equiv \log \left(v_{A A, t}\right)$. The realized volatilities are calculated from five-minute intraday returns. The dotted line refers to the standard normal density.

\section{Figure 3}

Unconditional Distribution of Standardized Daily Cor relations

The figure shows the unc onditional distribution of the standardized daily realized correlations between AA and XON, $\operatorname{Corr}_{A A, X O N, t,}$. The realized correlations are calculated from five-minute intraday returns. The dotted line refers to the standard normal density.

\section{Figure 4}

Time Series of Daily Logarithmic Standard Deviations

The figure shows the time series of the daily realized logarithmic standard deviations for AA, $l v_{A A, t} \equiv$ $\log \left(v_{A A, t}\right)$. The realized volatilities are calculated from five-minute intraday returns.

\section{Figure 5}

Sample Autocorrelations for Daily Logarithmic Standard Deviations

The figure shows the sample autocorrelations for the daily realized logarithmic standard deviations for AA, $l v_{A A, t} \equiv \log \left(v_{A A, t}\right)$, out to a displacement of 100 days. The realized volatilities are calculated from fiveminute intraday returns. The dotted line gives the minimum-distance estimates of the hyperbolic decay rate, $c \cdot h^{2 d-1}$. The dashed line give the upper range of the conventional Bartlett ninety-five percent confidence band. 


\section{Figure 6}

Volatility Scaling Plots for Daily Logarithmic Standard Deviations

The figure shows the logarithm of the variance of the partial sum of the daily realized logarithmic standard deviations fro AA, $\log \left(\operatorname{Var}\left[l_{A A, t}\right]_{h}\right)$, plotted against the logarithm of the aggregation level, $\log (h)$, for $h=$ $1,2, \ldots, 30$. The sample period extends from January 2, 1993 through May 29, 1998, for a total of 1,366 observations at the daily level. The daily realized volatilities are calculated from five-minute intraday returns. The dotted line refers to the least-squares estimates of the regression line $c+(2 d+1) \cdot \log (h)$.

\section{Figure 7}

Time Series of Daily Correla tions

The figure shows the time series of daily realized correlations between AA and XON, Corr $_{A A, X O N, t,}$. The sample period extends from January 2, 1993 through May 29, 1998, for a total of 1,366 daily observations. The realized correlations are calculated from five-minute intraday returns.

\section{Figure 8}

\section{Sample Autocor relations of Daily Correlations}

The figure shows the sample autocorrelations for the daily realized correlations between AA and XON, $\operatorname{Corr}_{A A, x O N, t}$. The realized correlations are calculated from five-minute intraday returns. The dotted line gives the minimum-distance estimates of the hyperbolic decay rate, $c \cdot h^{2 d-1}$. The dashed line give the upper range of the conventional Bartlett ninety-five percent confidence band.

\section{Figure 9}

Volatility Scaling Plots for Daily Correlations

The figure shows the logarithm of the variance of the partial sum of the daily realized correlations between AA and XON, i.e., $\log \left(\operatorname{Var}\left[\operatorname{Corr}_{A A, X O N, t}\right]_{h}\right)$, plotted against the logarithm of the aggregation level, $\log (h)$, for $h=1,2, \ldots, 30$. The sample period extends from Ja nuary 2, 1993 through May 29, 1998, for a total of 1,366 observations at the daily level. The daily realized correlations are calculated from five-minute intraday returns. The dotted line refers to the least-s quares estimates of the regression line $c+$ $(2 d+1) \cdot \log (h)$.

\section{Figure 10}

News Impact F unctions for Daily Logarithmic Standard Deviations

The figure shows the scatterplot of the daily realized logarithmic volatilities for AA, $l v_{A A, t}$, against the lagged standardized returns, $r_{A A, t-1} / l v_{A A, t-1}$. The solid lines refer to the estimated regression lines for the 
lagged returns being negative or positive. The realized volatilities are calculated from five-minute intraday returns.

\section{Figure 11}

News Impact F unctions for Daily Correlations

The figure shows the scatterplots for the daily realized correlations between AA and XON, Corr $_{A A, X O N, t}$, against the average lagged standardized returns, $1 / 2 \cdot\left(r_{X O N, t-1} / v_{X O N, t-1}+r_{j, t-1} / v_{j, t-1}\right)$. The solid lines refer to the estimated regression lines for the sum of the lagged returns being negative or positive. The realized correlations are calculated from five-minute intraday returns.

\section{Figure 12}

Scatterplot of Daily Realized Logarithmic Standard Deviations

The figure shows the scatterplot of realized daily logarithmic standard deviations for AA, $l v_{A A, t}$, against the logarithmic standard deviations for $\mathrm{XON}, l v_{X O N, t}$. The realized volatilities are calculated from five-minute intraday returns.

\section{Figure 13}

Scatterplot of Average Daily Realized Correlations versus Logarithmic Standard Deviations

The figure shows the scatterplot of the average realized daily correlations for AA, $(1 / 29) \cdot \Sigma_{i} \operatorname{Corr}_{A A, i, t}$ and $i \neq A A$, against the logarithmic standard deviations for $\mathrm{AA}, l v_{A A, t}$. The realized volatilities and correlations are calculated from five-minute intraday returns.

\section{Figure 14}

Scatterplot of Average Daily Realized Correlations

The figure shows the scatterplot of the average realized daily correlations for AA aga inst the avera ge realized correlations for XON; i.e., (1/28) $\Sigma_{i} \operatorname{Corr}_{A A, i, t}$ against $(1 / 28) \cdot \Sigma_{i} \operatorname{Corr}_{X O N, i, t}$ for $i \neq A A$ and $i \neq$ $X O N$. The realized correlations are calculated from five-minute intraday returns. 
Figure 1



Figure 2

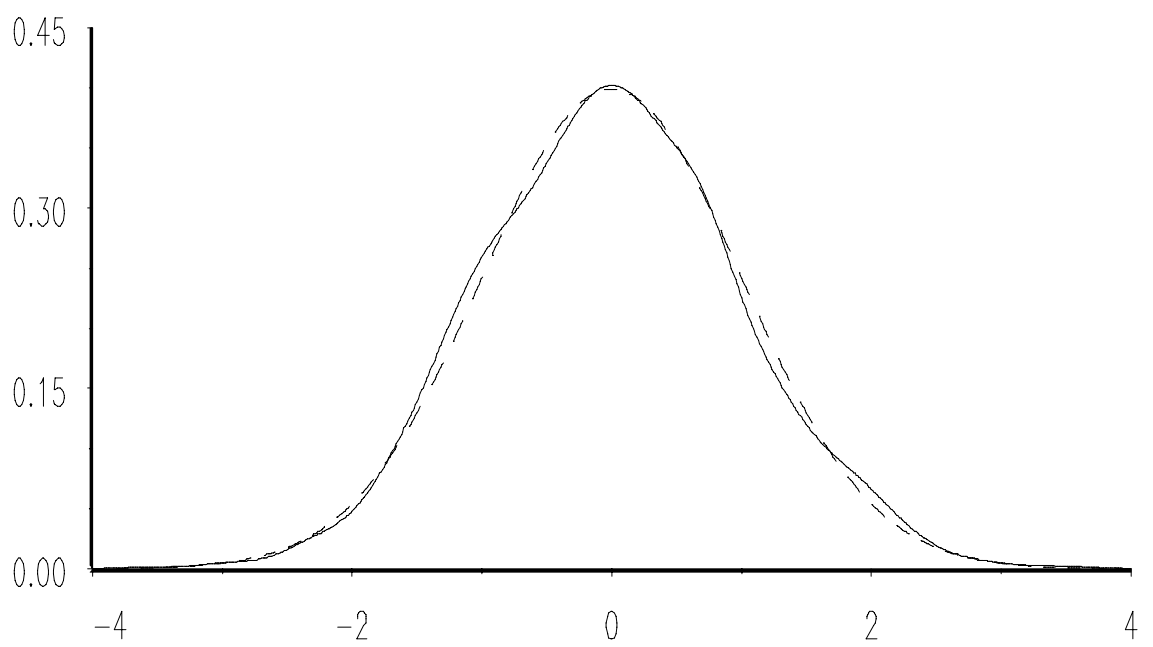

Figure 3

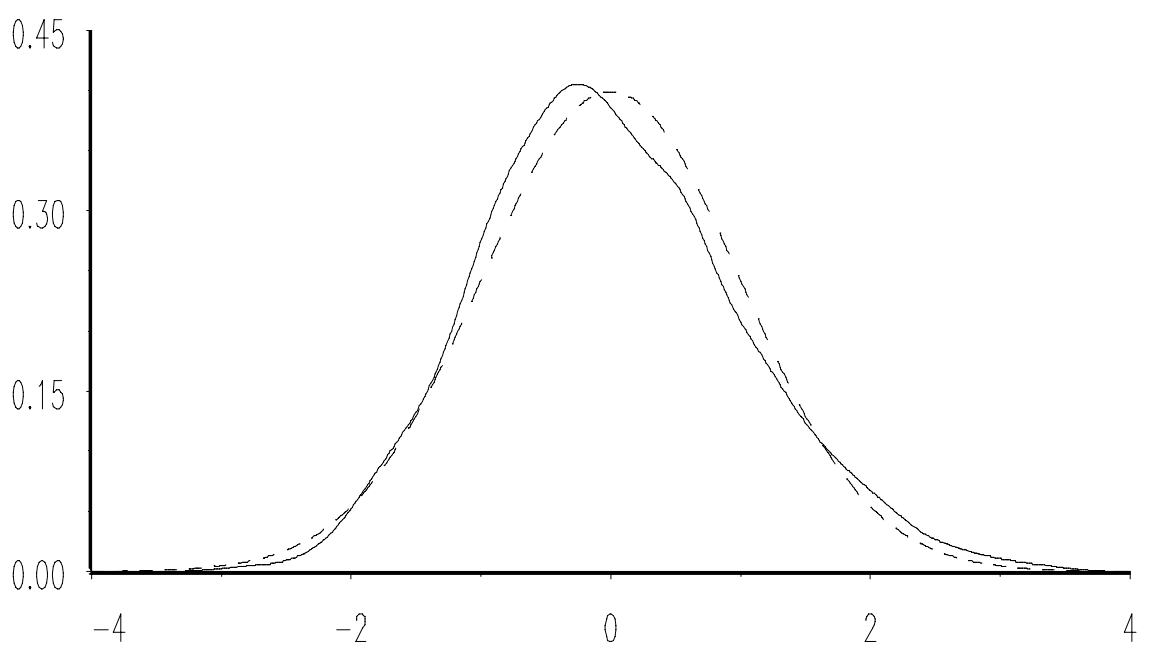


Figure 4

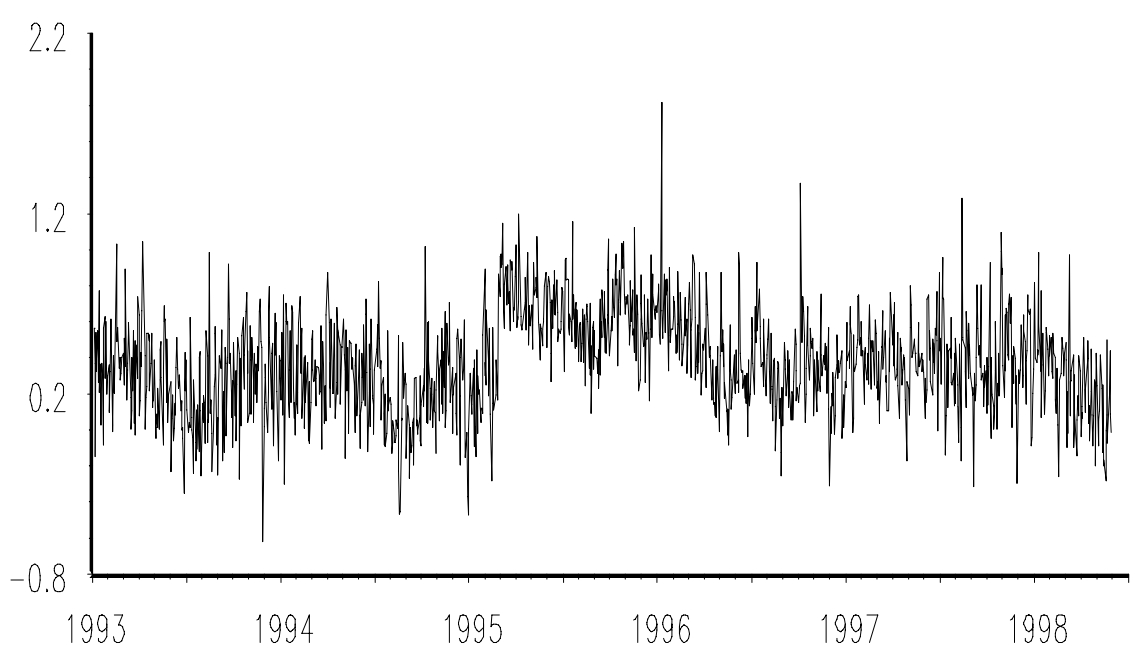

Figure 5

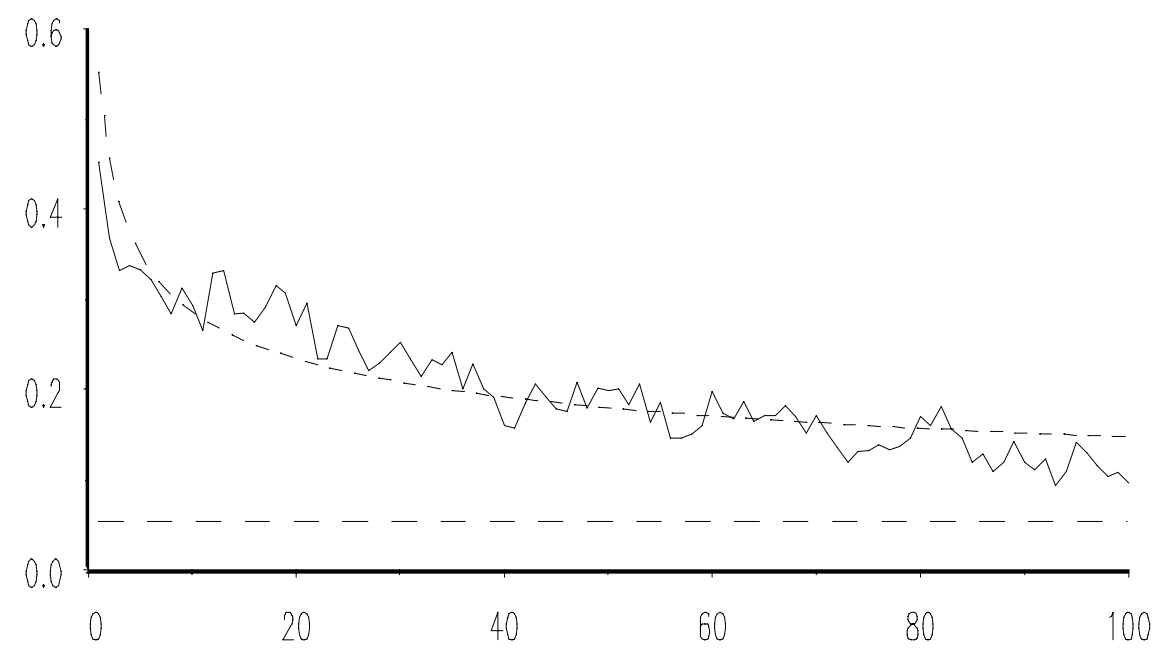

Figure 6

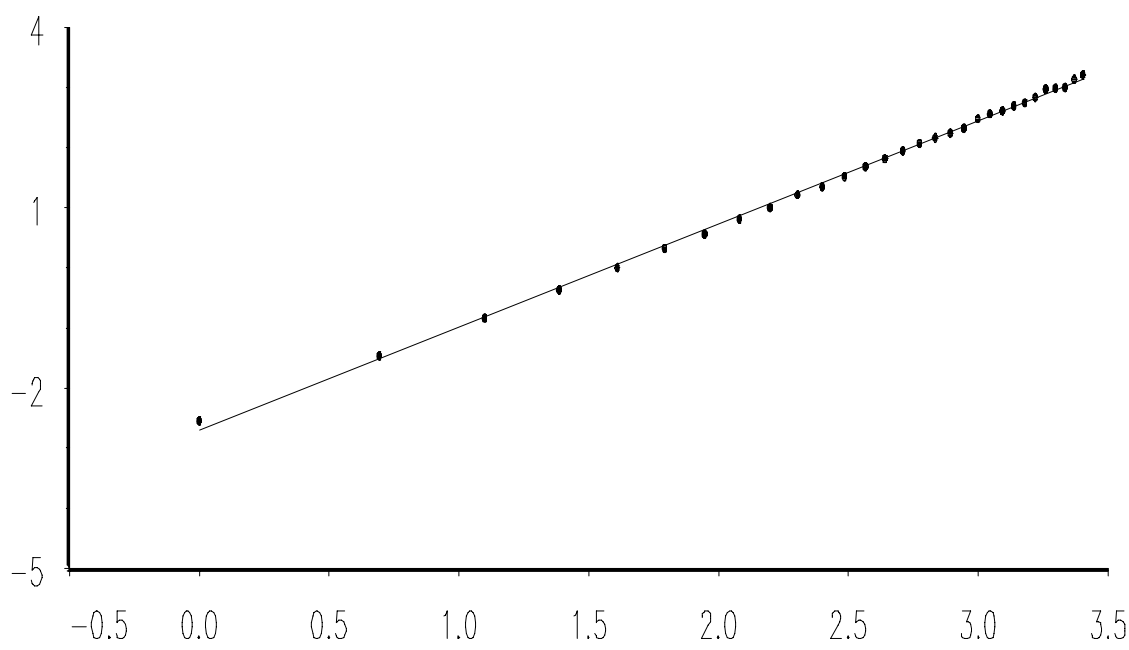


Figure 7

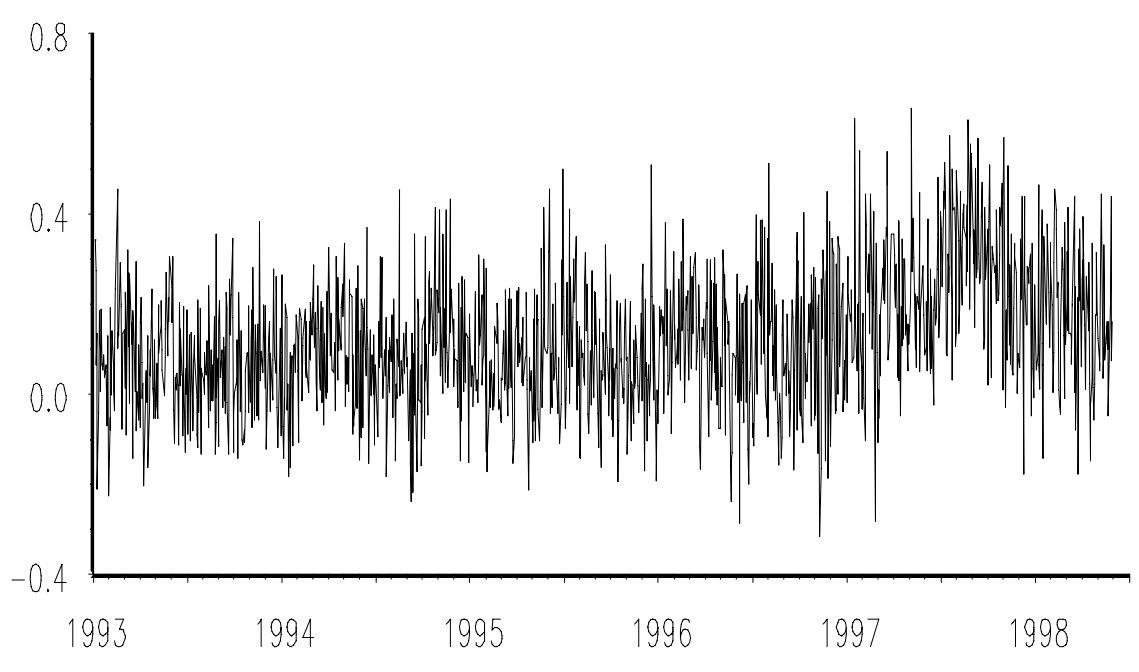

Figure 8

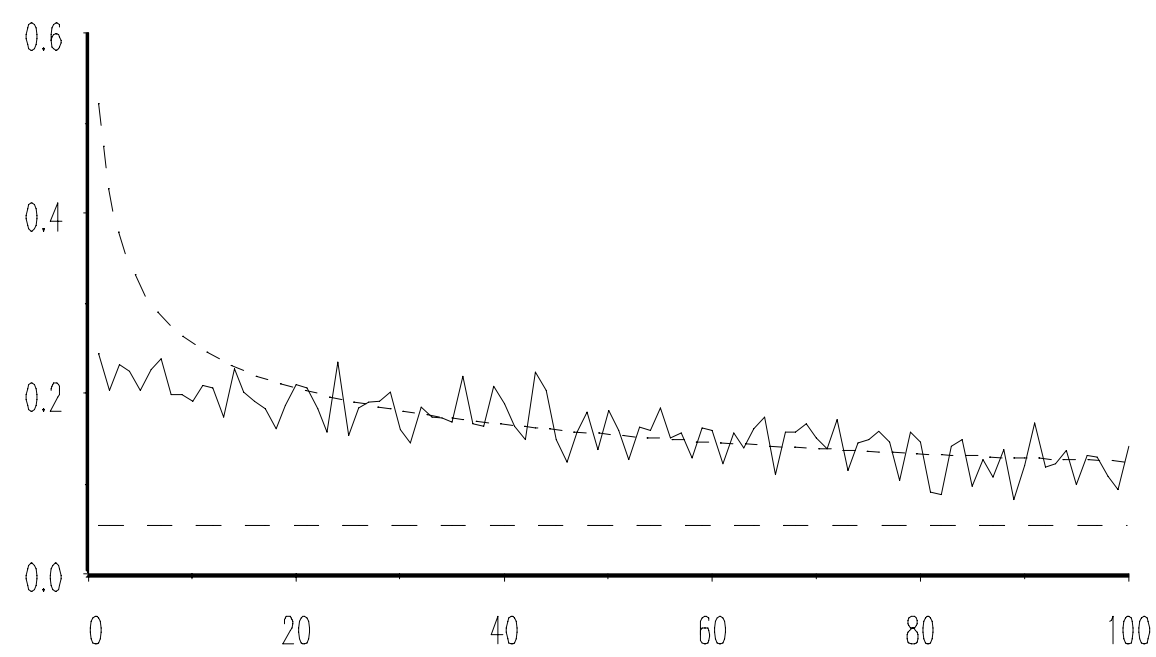

Figure 9

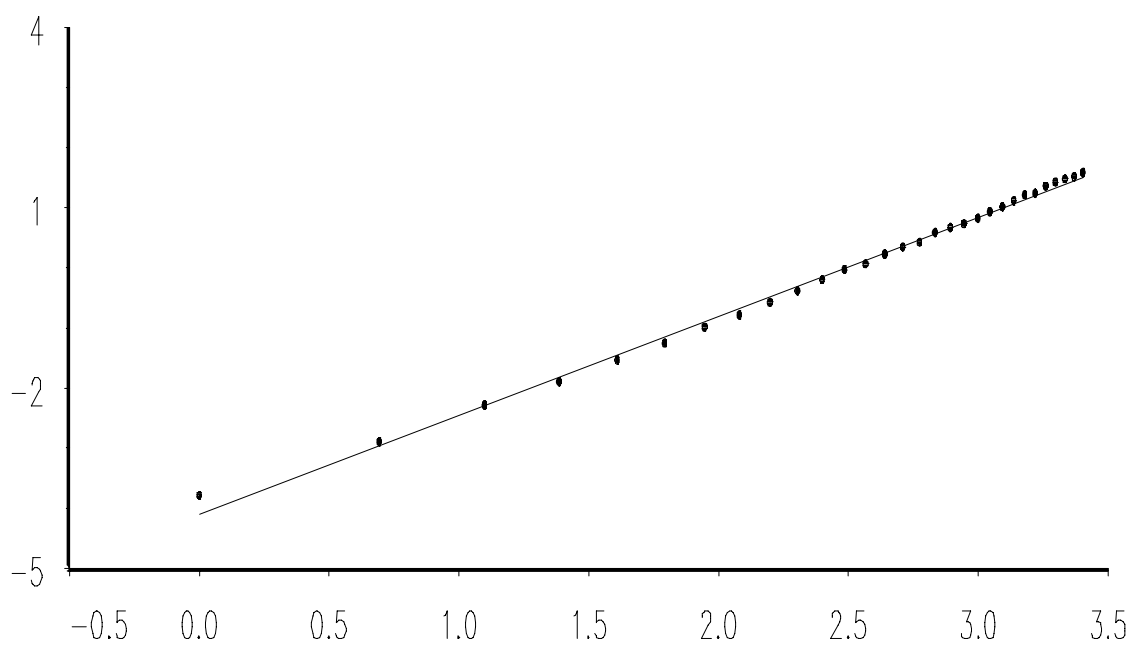


Figure 10



Figure 11




Figure 12



Figure 13

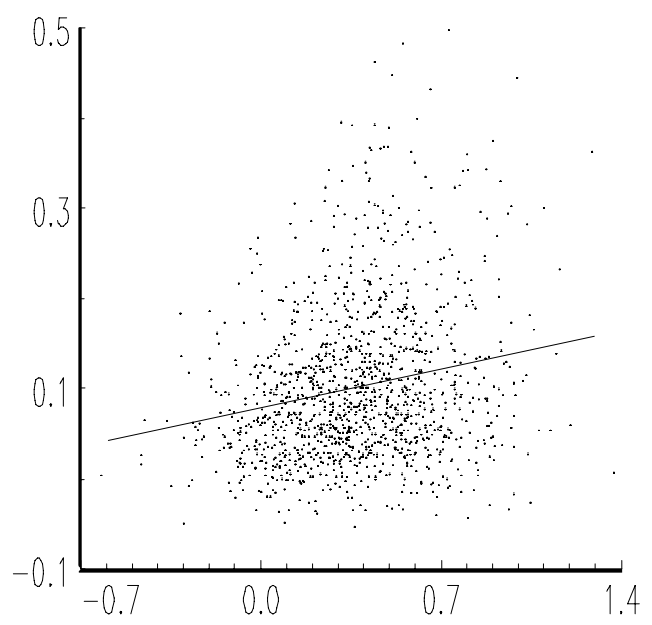

Figure 14

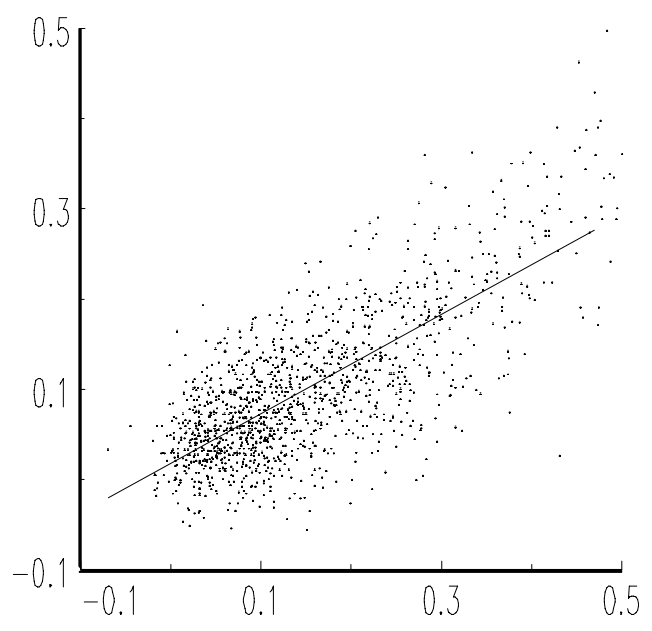

